\author{
A DISSETATION \\ SUMMITTED TO THE GRADUATE SCHOOL \\ IN PARTIAL FULFILLMENT OF THE REQUIREMENTS \\ FOR THE DEGREE \\ DOCTOR OF EDUCAITON \\ BY \\ CHANGSU LEE \\ DISSERTATION ADVISOR: DR. JOSEPH. ARMSTRONG
}

\author{
BALL STATE UNIVERSITY \\ MUNCIE, INDIANA \\ MAY 2011
}




\section{ACKNOWLEGMENT}

To my committee members; Dr. Joseph Armstrong, Dr. Thalia Mulvihill, Dr. Stacy Walker, Dr. Kathy Segrist, and Dr. Munni Begum, I am very thankful to you all for helping me to pursue my study. You are faithful to your duties and great dedicated educators. You also have professional knowledge and could take a unique perspective to my study. You helped me to learn how to select participants; how to use statistical methods; and how to find results of studies. Dr. Armstrong, you are my mentor and role model. You are always giving me to a positive attitude to study and also have a broad knowledge of my work. Without your assistance, this study would not have been successfully completed.

To my wife, YoungKyung Choi, we have been married for 10 years now. When I first came to the U.S for the study abroad, we just got married and helped a lot to finish my study. Five years ago, I encouraged to you study in your area and you started to study Special Education as a Master's Degree. Now, you also are in the Doctoral Degree program and working on pursuing your degree. I knew you had very difficult time when I was working on the dissertation process because you not only take care of our son (Luke Lee) as a mother, but also has to study your own fields. You always believe in me and I put forth my best effort. I am really thankful because you help me to believe I could attain my degree. To my lovely son, Luke Lee, you are now turning 8 years old. You are a very nice boy and I am always proud of your attitude. I remembered that one time while I studied at home, you understood what I was doing. You brought another chair and put it at my side and read your own books for a while. My family, you have all devoted so much, and stood by me to finish the study. 
I am very interest in studying about physical activity of older adults. I still like exercise, such as swimming, racket ball, soccer, running, golf, and basketball. Every time, while exercising, I can feel my body getting stronger, and my mind feels great. During exercise all of my concern was gone and it could refresh everything. People age and they can get disease and will die someday. I saw many old people who still enjoy physical activity. They are very healthy in both body and mind. This study is a good example of older adults that if they demonstrate regularly exercise, their exercise selfefficacy scale could increase. 


\section{TABLE OF CONTENTS}

ACKNOWLEDGEMENTS ................................................................................ii

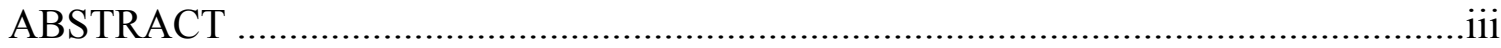

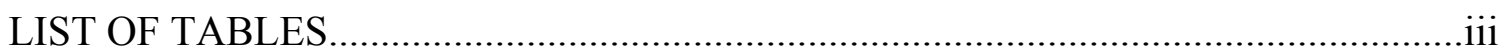

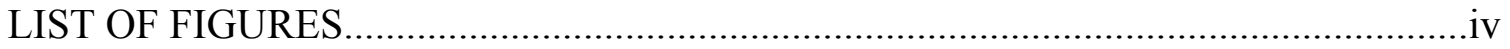

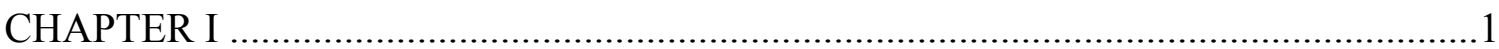

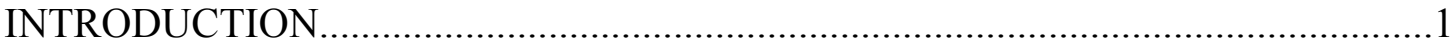

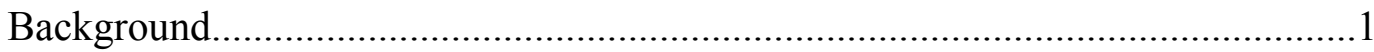

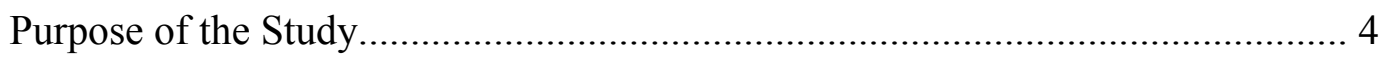

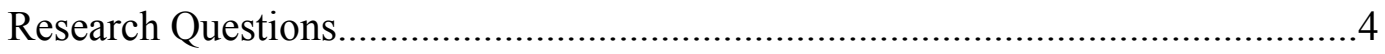

Hypotheses .............................................................................

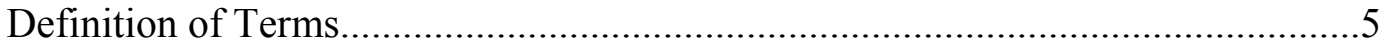

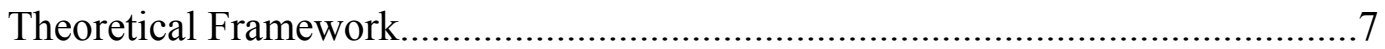

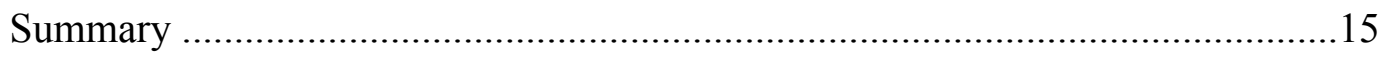

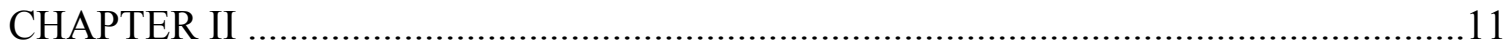

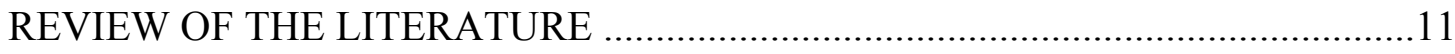

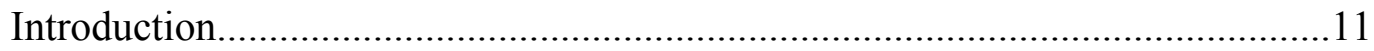

Growth of the Older Population and Age Related Change...................................11

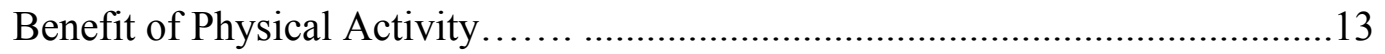

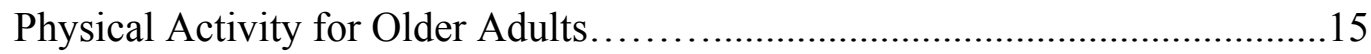

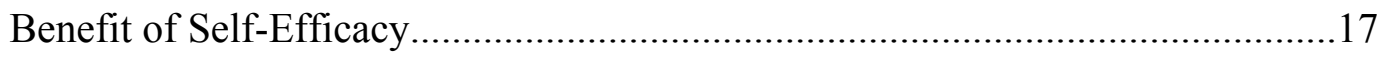

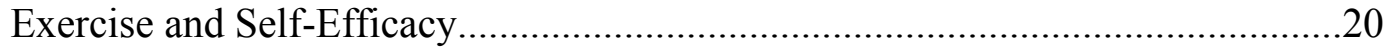




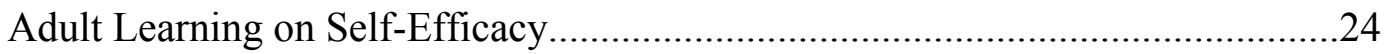

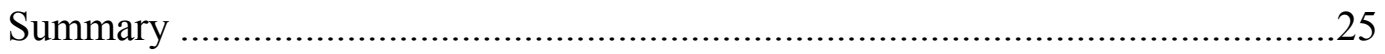

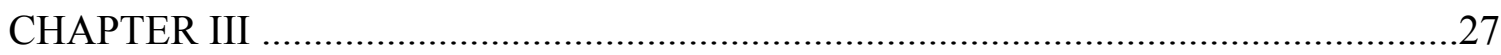

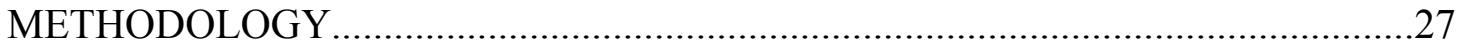

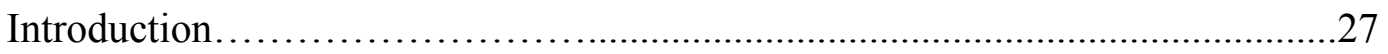

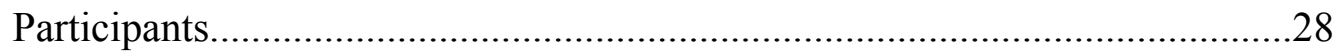

Procedures from Institutional Review Board (IRB) Approval and Informed

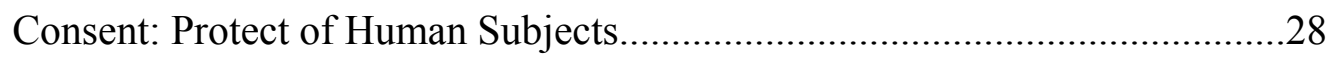

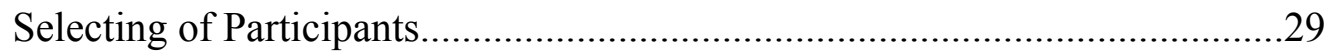

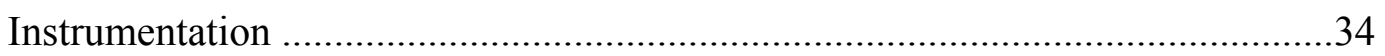

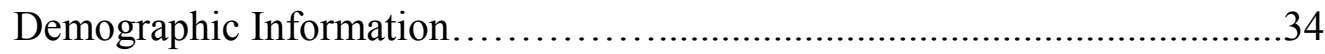

The Habitual Physical Activity Index........................................................34

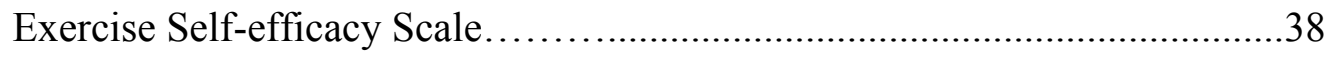

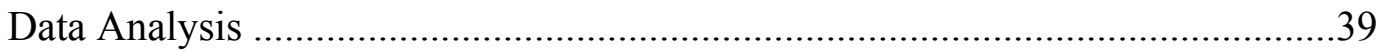

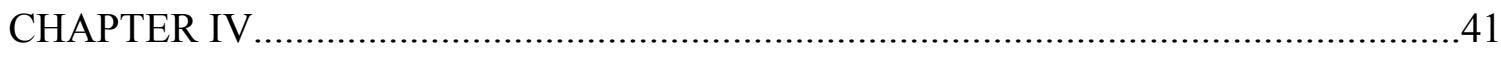

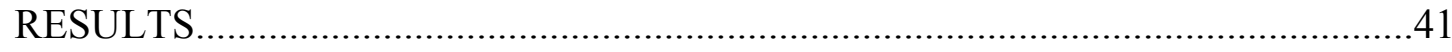

Purpose of this Study ...................................................................................

Data Analysis................................................................................................

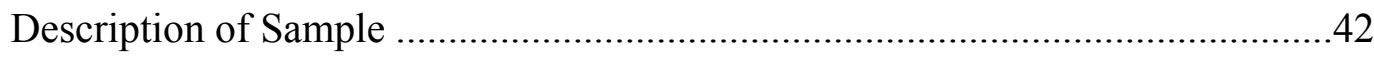

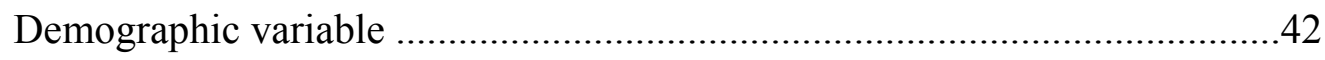

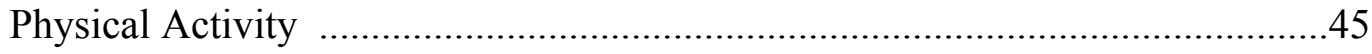

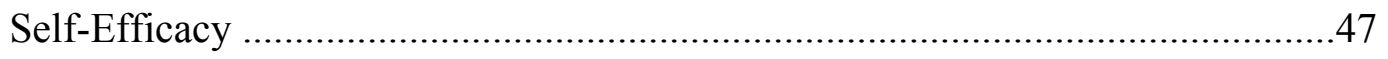

Data Analysis 
One-Way ANOVA..........................................................49

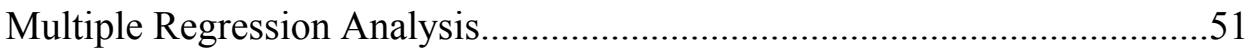

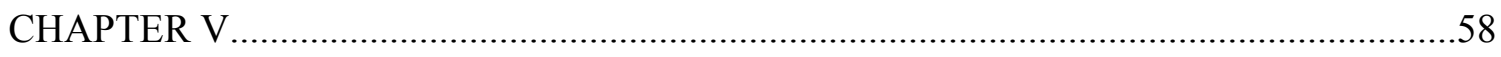

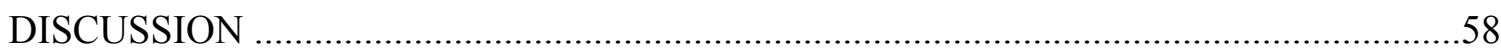

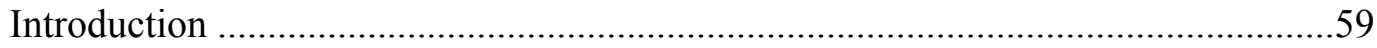

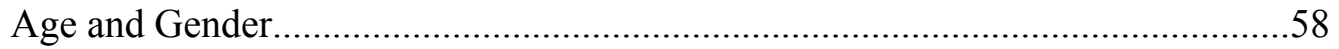

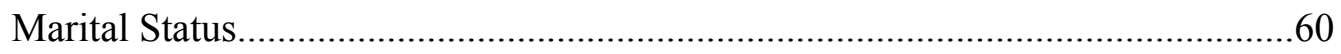

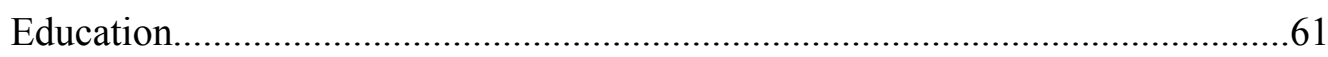

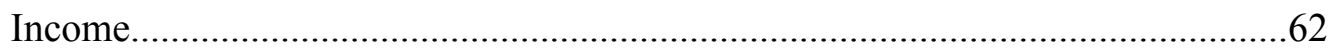

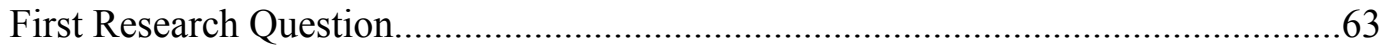

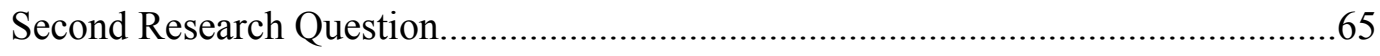

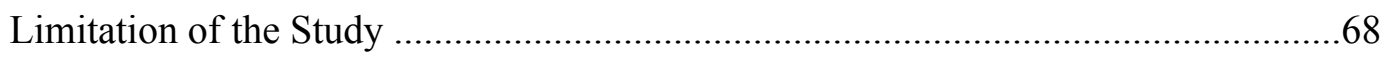

Suggestion for the Future Research............................................................. 70

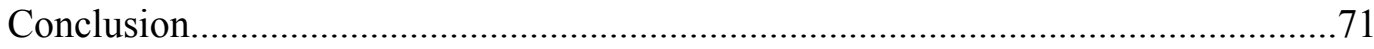

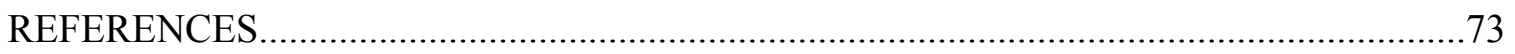

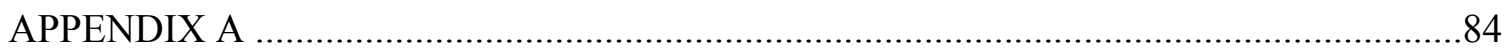

PROTECTING HUMAN SUBJECT RESEARCH PARTICIPANTS............................85

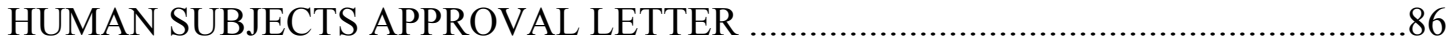

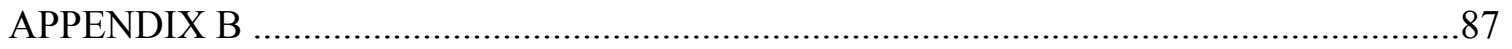

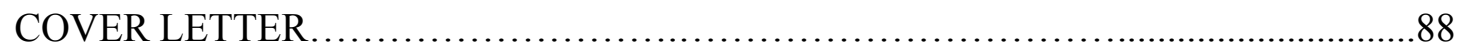

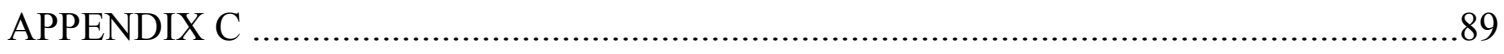

THE LETTER OF AGREEMENT (THE COMMUNITY CENTER FOR VITAL

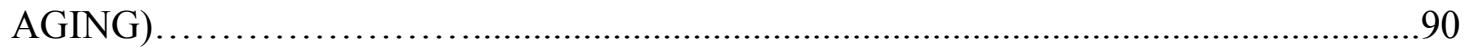


APPENDIX D

91

THE LETTER OF AGREEMENT (THE FOREST PARK SENIOR

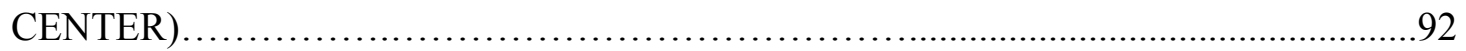

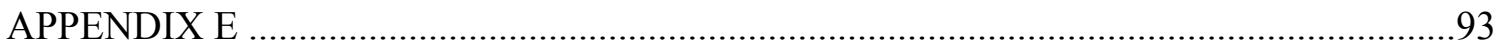

THE LETTER OF AGREMENT (THE RETIRED SENIOR VOLUNTEER

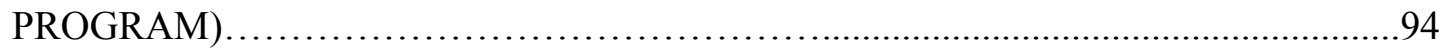

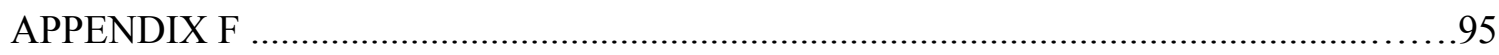

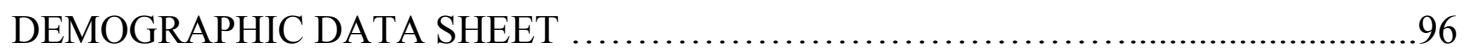

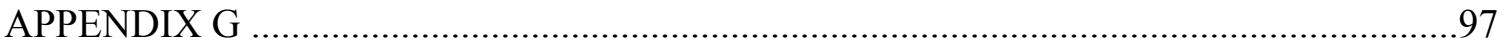

HABITUAL PHYSICAL ACTVIITY INDEX …..........................................98

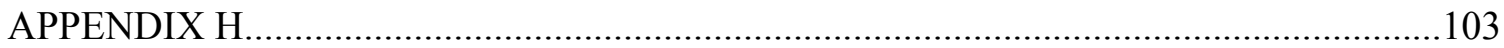

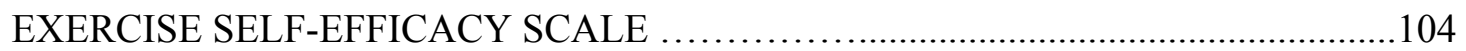




\begin{abstract}
The Center for Disease Control (2008) and William (2006) reported that the American older population has dramatically increased recently. Numerous studies found that when people get old, they are more likely to have functional disabilities with physical components. Frontera et al. (2000) and Doherty (2003) reported that older adults have significantly decreased muscle force and power. They also have a higher risk of chronic disease, arthritis, type 2-disabetes, obesity, and certain types of cancer compared to young adults (Grembowski et al, 1993; \& Wojtek et al, 2009). Self-efficacy is a person's belief in his or her ability to succeed in a particular situation (Bandura, 1997 and 1999), and several studies have shown that a strong sense of self-efficacy could maintain regular physical activity and change health behavior to reduce the risk of illness or mortality of older adults (CDC, 1999; \& MaAuley et al. 1997).

The current study examined the relationship between self-efficacy for exercise and level of physical activity for older adults. This study also examined the relationship between self-efficacy for exercise and the level of physical activity through various demographic dimensions including age, gender, marital status, years of completed education, and household income. Participants of the study were 50 years of age and older, who currently live in the Midwest. Two local senior centers and one volunteer group provided the participants. A total of 202 questionnaires were distributed to volunteer participants during the spring and summer of 2010, and 124 were returned.

Data analysis included the use of one-way ANOVA to determine the relationship between the self-efficacy for exercise and the level of physical activity. Multiple Regression determined the relationships between self-efficacy for exercise and the level of physical activity through the demographic variables. Results indicated that the exercise
\end{abstract}


self-efficacy scale positively related with leisure activity group. However, no differences were observed for the exercise self-efficacy scale by habitual and occupational physical activity. The results also indicate that significant correlations were found between age and exercise self-efficacy. Younger adults indicated that moderate and regular physical activity positively affected their exercise self-efficacy.

The findings suggest that young adults who engage in more physical activity attain more favorable exercise self-efficacy than older adults. The conclusions indicate that some differences were observed between the level of physical activity and exercise self-efficacy, and these findings add to our understanding of the physiological and cognitive benefits of physical activity, and its impact on older adults' cognitive perspectives. 


\section{LIST OF TABLES}

1. Participants............................................................ 33

2. Demographic Characteristics of Participants...............................43

3. The Result of One-Way ANOVA for Self-Efficacy and Level of Physical

Activities.............................................................50

4. Leven's Test of Equality of Error Variances..................................51

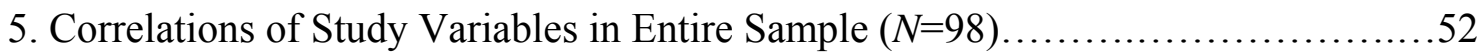

6. Summary of Multiple Regression for Predicting Exercise Self-Efficacy Scale ......55

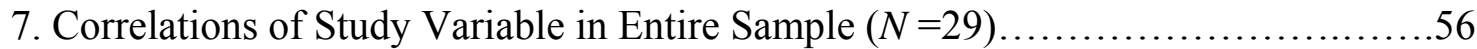




\section{LIST OF FIGURES}

1. Response Percentage of Participants' Level of Education......................... 44

2. Response Percentage of Participants' Household Income $\quad$.......................45

3. Response Rate of Physical Activity........................................46

4. The Normal P-P Plot of Regression Standardized Residual Dependent Variable:

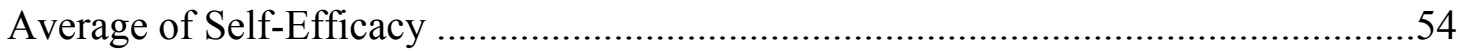

5. The Normal P-P Plot of Regression of Standardized Residual Dependent Variable:

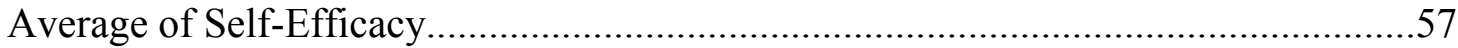




\section{CHAPTER I \\ INTRODUCTION}

\section{Background}

People live longer, and they remain increasingly active and productive. I believe it is a good sign for our society. However, the social system for older people has not always kept up with their satisfaction. Health is a very important issue for older adults because it is an aspect of life which affects older individuals, family and society. Many older Americans recognize that rising health care costs are a menace to their financial security.

Self-efficacy is a person's belief in his or her ability to succeed in a particular situation. These beliefs are made from a person's feeling, thought, motivation and conduct (Bandura, 1977 and 1999). A strong sense of efficacy reinforces personal attainment and well-being in various ways. People with full confidence can manage the exceptionally difficult tasks with surprising capabilities rather than give up their tasks.

Compared to younger people, older adults may have lower self-efficacy, because self-efficacy expectations may become lower with age (Gaithersburg, 1999). DavisBerman (1989) reported that there were significant differences between young and older adults about self-efficacy levels and young adults presented higher self-efficacy in general day to day living situations.

Self-efficacy not only has been identified as an important part of health behavior in older adults (Perkins, Multhaup, Perkins \& Barton, 2008), but also has been associated with greater life satisfaction (White, Wojcicki \& McAuley, 2009). Self-efficacy expectations have continuously been recognized as important determinants of health 
behavior in older adults (Grembowski et al., 1993; Strecher, DeVellis, Becker \& Rosenstock, 1986).

Several studies found that a high level of self-efficacy has many benefits for adults and their well being (Magaletta and Oliver, 1999). People with high perceived selfefficacy are more likely to show positive results both physically and mentally. They show better health condition and less psychological symptoms such as depression, stress or fatigue (Weber et al., 2003). They can also recover better and more rapidly from illness and injury compared to people with low self-efficacy (Bandura, 1992; Gecas, 1989; Grembowski et al., 1993).

Self-efficacy has important theoretical and practical applications for health promotion and disease prevention among older adults. In performing specific health behaviors, people with high self-efficacy are more likely to stop negative behaviors cigarette smoking, control behaviors- weight control and diet, and health behaviorsexercise (Dino, Kamal, Horn, Kalsekar and Fernandes, 2004).

Now more than ever before, researchers have the evidence to very precisely state that strong self-efficacy enhances academic success and goal setting in adult education. Self-efficacy or self-confidence is a general feeling of being able to successfully learn and complete most tasks (Lent, Brown, \& Larken, 1987; Semmar, 2006; West, Welch, \& Thorn, 2001).

The relationship between physical activity and health has shown very positive results from accumulated evidence. Current findings indicated that the greater amount of exercise or participating in regular exercise enhances wellness and reduces the prevalence of chronic diseases (Corbin, 2008). Indiana State Department of Health found that in 
2000 , chronic diseases were the leading cause of death ( $75 \%$ or 55,209 deaths), with cancer and diabetes causing more than $65 \%$ of the total deaths (Indiana State Department of Health [ISDH], 2000).

As mentioned earlier, regular physical activity decreases the risk of cardiovascular disease, heart disease, diabetes, and high blood pressure (CDC, n.d.). However, many adults lead sedentary lives that are void of even the most basic health promoting activities. A recent report in Healthy People 2010 stated that more than $28.7 \%$ of adults were physically inactive during the previous month (Public Health Service, 2000).

The Center for Disease Control has developed the Behavioral Risk Factor Surveillance System (BRFSS) in order to better measure patterns and trends in physical activity. The Indiana State Department of Health (ISDH, 1994) used the BRFSS for over 20 years to collect information about health behaviors and preventive practices of adult ages. They had found that $29.7 \%$ of adults in Indiana were physically inactive which meant one fourth of adults did no physical activity during the previous month (ISDH). Therefore, the current lack of physical activity in the United States is in need of improvement.

Regular physical activity is known to provide greater health benefits, but, it is difficult to change people's behavior when they are not regularly physically active in their lives. Moreover, it is generally acknowledged to be true that there are many obstacles that hamper efforts to modify well-ingrained habits. To promote the ability of older adults who are attempting to change their health behaviors, they need to encourage self-efficacy and promote self-responsibility (Gleeson-Kreig, 2004) 


\section{Purpose of the Study}

The purpose of this study is to examine the relationship between self-efficacy for exercise and the level of physical activity for older adults who live in Delaware County, Indiana. This study also examined the relationship between self-efficacy for exercise and the level of physical activity through various demographic dimensions including age, gender, marital status, years of completed education, and household income. The study sample population is 124 older adults age fifty or older.

\section{Research Questions}

This research study was examining questions about the relationship between physical activity and perceived exercise self-efficacy for older adults. Two research questions are posed.

(1) What is the relationship between exercise self-efficacy and level of physical activity among older adults?

(2) What relationships exist in exercise self-efficacy and physical activity level by age, gender, marital status, level of education, and level of income among older adults?

\section{Hypotheses}

Based on the review of related literature, the following hypotheses have been generated:

It is hypothesized that (1) people with a higher level of physical activity are more likely to have higher self-efficacy for physical activity and (2) people with high level of education and income are more likely to have higher self-efficacy for physical activity. 


\section{Definition of Terms}

The following terms were significant to this study:

\section{Exercise}

A subcategory of physical activity; it is physical activity that is planned, structure and repetitive (Bess \& LeighAnn, 2003).

\section{Inactivity}

Not engaging in any regular pattern of physical activity beyond daily functioning (CDC, 1996).

\section{Leisure-time Physical Activity}

Leisure-time physical activity is physical activity that is performed during exercise, recreation, or any additional time other than that associated with one's regular job duties, occupation, or transportation (CDC, 1996).

\section{Moderate-intensity Physical Activity}

Moderate-intensity physical activity generally requires sustained rhythmic movements and refers to a level of effort equivalent to a "perceived exertion" of 11 to 14 on the Borg scale 3 to 6 metabolic equivalents (METs); any activity that burns 3.5 to 7 Calories per minute $(\mathrm{kcal} / \mathrm{min})$; or the effort a healthy individual might expend while walking briskly, mowing the lawn, dancing, swimming, or bicycling on level terrain (CDC, 1996).

\section{Older Adult}

Older adults are defined as those ages 50 and older (CDC, 2008). Older adults at the age over 50 are in the baby boomer generation and the researcher select that age group to include as large a sample of older adults as possible for this study. 
Physical Activity

Any bodily movement that results in the burning of calories (Bess \& LeighAnn, 2003).

\section{Regular Physical Activity}

A pattern of physical activity is regular if activities are performed most days of the week, preferably daily; 3 or more days of the week if moderate-intensity activities are chosen; or 3 or more days of the week if vigorous-intensity activities are chosen (CDC, 1996).

\section{Sedentary}

In the scientific literature, sedentary is often defined in terms of little or no leisure-time physical activity. A sedentary lifestyle is a lifestyle characterized by little or no physical activity (CDC, 1996).

Self-efficacy

People's beliefs about their capabilities to produce designated levels of performance that exercise influence over events that affect their lives (Bandura, 1994). Vigorous-intensity Physical Activity

Vigorous-intensity physical activity generally requires sustained, rhythmic movements and refers to a level of effort equivalent to a "perceived exertion" of 15 or greater on the Borg scale; greater than 6 metabolic equivalents (METs); any activity that burns more than $7 \mathrm{kcal} / \mathrm{min}$; or the effort a healthy individual might expend while jogging, chopping wood, participating in high-impact aerobic dancing, or swimming (CDC, 1996). 


\section{Theoretical Framework}

\section{Social Cognitive Theory}

At the beginning of the 1950s, many researchers started to study human behaviors in their social contexts instead of studying animal behavior in boxes. The social cognitive approach was known as "social learning” theory. During the 1970s, researchers had adopted the name of "social cognitive". The change in terminology was remarkable. There were two main features of contemporary theorizing: (1) that human thought processes, or "cognitive" processes, should be the main point of analyses of personality; and (2) that humans acquire their thoughts by themselves and also from the social interaction. The theory, therefore, is "social-cognitive" (Cervone \& Pervin, 2008).

Psychologist Albert Bandura lies at the center of this theory. The Social Cognitive theory is closely related to health communication. It provides a basic structure for understanding, forecasting and changing human behavior. Human behaviors are described as being changed and controlled by environmental influences or driven by internal tendencies. Social cognitive theory contains three human behaviors as an interaction of personal factors, behaviors, and the environment. Bandura (1977, 1986, 1999, and 2001) determined this form of psychosocial functioning "triadic reciprocal causation". In this model of reciprocal causation, several factors work closely together. Those factors are behavior, cognition and other personal factors, and environmental influences. Three functions rely on each other and influence one another bidirectionally.

First of all, cognitive psychologists study the interactive relationship between thought (personal function) and action (behaviors). They examined what people think, believe and feel affects how they behave. Moreover, social psychologists studied the 
relationship between thought (personal function) and the environment. They examined how environmental influences in the form of social persuasion, modeling, and change cognitions.

According to Glanz, Rimer, and Lewis (2002), environmental function can affect a person's behavior, and it can be divided by two areas which are social and physical environments. Social environment refers to friends and family members. Physical environments refer to the size of a room, and surrounding temperature or the use of specific foods. Situation also can affect a person's behavior. It is a person's perception of the time, physical conditions and activity.

Behavior could not simply be measured by the result of the environment. The environmental function also could not simply be measured by the result of the personal behaviors. According to Bandura (1999), it is in need of a dynamic interaction among personal determinants, behavior and environmental influences. In triadic causation, there is no strait pattern for reciprocal interaction. Partially, each factor is affected by the level of activities, situational circumstances, socio-structural constraints and opportunities.

Why has self-efficacy become such an important topic among psychologists and educators? As Bandura and other researchers amply confirmed self-efficacy can have a strong influence on everything from psychological states to behavior to motivation. The personal decision is based on the self-beliefs of efficacy, identified goals, quality of analytic thinking, and affective self-reaction (Bandura, 1992).

\section{Self-Efficacy}

Bandura (1994) defined the perceived self-efficacy as "people's beliefs about their capabilities to produce designated levels of performance that exercise influence over 
events that affect their lives" (p. 1). In other words, self-efficacy is a person's belief in his or her ability to succeed in a particular situation. These beliefs determine how people feel, think, motivate themselves, and behave.

A strong sense of efficacy reinforces personal attainment and human well-being in various ways. People with full confidence can manage the exceptionally difficult tasks with surprising capabilities rather than give up their tasks. A high sense of efficacy can develop personal interest and devote to certain types of difficult tasks. People try to challenge themselves in a high level of goals and make strong commitments to succeeding in these goals. They are stepping up their effort in the face of failure. They get back their sense of efficacy from the disappointment or failures. They can keep practicing over and over to get there. Such kinds of efficacious outlook yield personal accomplishments, and it also reduces stress and depression (Bandura, 1994).

According to social cognitive theory, people's beliefs about their efficacy are influenced by information from four main sources. First of all, the best way to create a strong sense of efficacy is through mastery experiences. Bandura (1994) explained that when people experience failure, they get over their difficulties, and drive to overcome all obstacles. After having experiences about failure, people know what it takes to succeed and quickly recover from setback.

Second, creating a strong sense of efficacy through the various experiences comes from social models. Specifically, people have strong capabilities to accomplish their tasks when they are watching someone's success from the enormous effort. On the other hand, people might lose their own ability to succeed if they observe others fail in spite of enormous effort. 
Third, social persuasion is another way of developing strong sense of selfefficacy. When you listen to words of cheer from other members, it helps people achieve a goal from difficult tasks or helps people overcome self-doubt.

Lastly, positive mode also plays an important role in self-efficacy. For instance, when people are very nervous about presenting public speeches, their level of selfefficacy will decrease dramatically. In this case, people are also suffering from fatigue, aches and pains as signs of physical debility. Bandura (1994) mentioned "it is not the sheer intensity of emotional and physical reactions that is important but rather how they are perceived and interpreted."

Summary

Self-efficacy is a person's belief in his or her ability to succeed in a particular situation. These beliefs are made from a person's feelings, thoughts, motivations and conduct. A strong sense of efficacy reinforces personal attainment and human well-being in various ways. People with full confidence can manage the exceptionally difficult tasks with surprising capabilities rather than give up their tasks. 


\section{CHAPTER II}

\section{REVIWE OF THE LITERATURE}

\section{Introduction}

The literature reviewed for this research endeavor has been separated into six categories: Growth of the older population and age related change, the benefit of physical activity, physical activity for older adults, the benefit of self-efficacy, exercise and selfefficacy and adult learning on self-efficacy.

The first category covered studies that have begun to build a base of knowledge regarding the increasing size of the older population, and reviewed normal changes in body composition.

The second and third categories covered the benefit of physical activity and gave evidence of the relationship between regular exercise and reduction in an older person's changes from variety of diseases such as chronic heart disease.

Self-efficacy has important theoretical and practical applications for health promotion and disease prevention among older adults. A high level of self-efficacy has a lot of benefits for adults and their well being. Therefore, the fourth categorie was covered the benefit of self-efficacy both mental health and physical health of adults.

The fifth category briefly reviewed the relationship between physical activity and self-efficacy of older adults. Lastly, it covered adult learning on self-efficacy.

\section{Growth of the Older Population and Age Related Change}

In the United States, the American older population has significantly increased recently. The research by Atchley (2000) studied the proportion of people at the age of 65 and older. The study showed that the number of people at the age of 65 or more tripled 
from 1950 (12.4 million) to 2000 (34.7 million) and this number was expected to double by the year 2040 ( 75.2 million). The growth in those over 65 was strong because the people born between 1946 and 1964, called the baby boom generation reached the age of 65 by 2030 and they may exceed $20 \%$ of the population. The other reason was that the fertility rates not only rapidly decreased, but also people are living longer than before (CDC, 2008; William, 2006).

As the body ages, it has deep effects on health and physical function among older adults. Older adults disclosed the highest rate of degenerative musculoskeletal conditions including osteoporosis, arthritis, and the decrease in the size of muscle (Wojtek et al., 2009).

Normally, older adults at the age of 60 showed significant decrease of their muscle force and power. Frontera et al. (2000) and Doherty (2003) both studied human muscle force and the study showed that the maximum voluntary force of contraction was decreased by $20-40 \%$ on average in the proximal and distal muscle of both genders at the ages between 70 and 80 .

Harridge, Magnusson and Saltin (1997) also studied the muscle force and power decrease of elderly men. According to the research, the results showed that the muscles of men aged 70-100 years old $(N=15)$ were $40 \%$ weaker than the muscles of young men aged 21-35 year old $(N=17)$.

In addition, Grembowski et al. (1993) reported that when people are getting old, they are more likely to have functional disability and a risk of developing or dying from chronic disease such as cardiovascular disease, type 2 diabetes, obesity, and certain cancers. 
Shephard (1997) studied age-related changes in the distribution of subcutaneous fat. This study showed that older adults at an age over 65 increased their body fat about $43 \%$, whereas in older women indicated an overall there was increased about $75 \%$ compared to young people at the age of 25 . The main reason for the accumulation of fat was that older people reduced their habitual physical activity, reduced resting energy expenditure, and reduced daily energy requirements.

It is therefore necessary for older adults to be particularly attentive to health maintenance behaviors and health lifestyles within physical, emotional, and psychological dimensions (Morris, McAuley, \& Motl, 2008).

\section{Benefit of Physical Activity}

Regular physical activity is very important for sustaining body health, enhancing mind control and preventing premature death. It is very important for sustaining body health, enhancing mind control and preventing premature death of older adults. Wojtek et al. (2009) mentioned that older adults engaged at least some daily physical activity and refusing sedentary lifestyle may reduce the risk of developing chronic diseases and sustaining premature death at any age.

For example, a 70 year old will never make a new 100 meter record because of unavoidable results of aging; nonetheless, a 70-year old person who has cross-country skied over 40 years seems to be much better able to work out than a 35 -year-old overweight smoker who has not done the minimum to achieve the recommended amount of physical activity (Shephard, 2002).

In recent years, the relationship between physical activity and health has shown very positive results from accumulated evidence. Now more than ever before, researchers 
have the evidence to very precisely state that regular exercise enhance wellness and reduce the chronic diseases which are the leading $70 \%$ of causes of death in the United States (Corbin, 2008).

In 1996, the U.S. Surgeon General reported on physical activity and health dealing with the benefits of regular physical activity, major public health concern, and the status of the current percentage of physical activity. The report was made up of the evidence dealing with physical activity and health from 1991 to 1995 research results. As was mentioned earlier, regular physical activity performed on most days of the week decreases the risk of illness such as cardiovascular disease, heart disease, diabetes, and high blood pressure (Center for Disease Control and Prevention, n.d.).

People who lived in urban environments live with isolated and sedentary lifestyles because of higher rates of sedentary behaviors (ie, watching television, increased computer usage, and rare interactions with neighbors. Shobha, Liam and Allen (2003) reported that this isolation may lead people to obesity, increased cardiovascular disease and mental health problems. The trends in physical activity should be considered as a whole.

According to Healthy People 2010, only 15 percent of adolescents were performing the recommended amounts of physical activity and 40 percents of adults were not engaging in regular physical activity in 1997 (Public Health Service, 2000). That means more than 55 percent, the majority of Americans, are minimally physically active and do not achieve the recommended amount of physical activity. However, 65 percent of students at the age 15 through 18 were achieving the recommended amount of regular physical activity in 1999 . 
The National Health Interview Survey (NHIS) was used to collect data from 1985, 1990, and 1991 to determine current physical activity trends of randomly selected US adults ages 18 and older. In 1985, 36,399 people were randomly selected. In 1990, 41,104 individuals were randomly selected and in 1991, 43,732 were selected. As part of the survey, participants were interviewed in their family home about their physical activity trends the previous weeks. The overall response rate was 83 to 88 percent. In the 1991 , they found $24.3 \%$ of adults had not been physically activity in the previous weeks. The prevalence of regular, vigorous leisure time activity showed by U.S. adults was approximately $15 \%$. Moreover, walking was the most commonly reported leisure time physical activity (CDC, 2000).

Experts advised that "people of all ages should include a minimum of 30 minutes of physical activity of moderate intensity (such as brisk walking) on most, if not all, day of the week. It is also acknowledged that for most people, greater health benefits can be obtained by engaging in physical activity of more vigorous intensity or of longer duration" (Public Health Service [PHS], 1996).

\section{Physical Activity for Older Adults}

U.S. Department of Health and Human Services (2009) made guideline of exercise and physical activity of older adults. The guidelines state that "All older adults should avoid inactivity. Some physical activity is better than none, and older adults who participate in any amount of physical activity gain some health benefits." The guideline emphasize that "older adults should do at least 150 minutes ( 2 hours and 30 minutes) a week of moderate-intensity, or 75 minutes ( 1 hour and 15 minutes) a week of vigorousintensity aerobic physical activity, or an equivalent combination of moderate- and 
vigorous-intensity aerobic activity. Aerobic activity should be performed in episodes of at least 10 minutes, and preferably, it should be spread throughout the week."

Wojtek et al. (2009) mentioned that older adults engaged at least some daily physical activity and refusing sedentary lifestyle may reduce the risk of developing chronic diseases and sustaining premature death at any age.

Older adults who participated in regular aerobic exercise showed massive physiological and health advantages compared to sedentary older adults. Specifically, Goodpaster, Costill, Trappe, \& Hughes (1996) studied the relationship of sustained exercise training and bone mineral density in aging male runners. The researchers collected data on male adults aged 42 to 73 who had experience with competitive distance running for over 20 years. The researchers divided them into three groups as being highly trained, moderately trained and untrained. They found that an untrained group had significantly greater total body weight and fat than in either the moderate trained and highly trained group.

Regular physical activity may reduce cardiovascular and metabolic stress for older persons (Wojtek et al. 2009). The researchers have examined the hemodynamic responses between regular exercise groups at the age over 56 who did run $10 \mathrm{~km}$ local marathon for a 3 month period and healthy older sedentary groups. The results showed that the maximal $\mathrm{O} 2$ consumption ( $\mathrm{VO} 2 \mathrm{max}$ ) of the exercise group was $47 \%$ higher when expressed per kilogram of body weight than that of the sedentary group (Hagberg, et al. 1985). High VO2max represents the amount of oxygen the body can use in one minute at maximum capacity (Turnquist, 2009). Therefore, higher percentage oxygen users have healthier cardiovascular system. 
Regular physical activity also showed a significantly reduced coronary risk profile. Williams (1998) studied the relationship between coronary heart disease risk factors and vigorous exercise in older adults. The researcher surveyed male older runners at the age over $70(\mathrm{n}=175)$, at the age over $60(\mathrm{n}=935)$ and young male runners $(\mathrm{n}=8,672)$. From the study, runners over age 60 who ran longer distance displayed significantly higher plasma high-density lipoprotein (HDL) cholesterol levels, and lower adiposity, blood pressure and triglycerides. Moreover, male runners at age over 60 and 70 were expected to have reduced heart disease risk by doing their vigorous activity.

Regular physical activity had a lower chance of developing disability in old age or premature death (Wang, Ramey, Schettler, Hubert, \& Fries, 2002). The researchers examined the quantitative study about the benefit of aerobic exercise such as running with elderly. They examined over 13 years with 370 runners at an age over 50 older and 249 control groups at ages 50 to 72 years who did not regularly exercise and tested both groups using the Health Assessment Questionnaire disability score. From the testing, they found that regular runner's club members had protection against disability and premature death. For instance, elderly who participated in regular exercise had their life expectancy increased by 8.3 years more compared to people who never run. Furthermore, people who never run had a 3.3 times higher risk of death than regular runners' club members.

\section{Benefit of Self-Efficacy}

Several studies found that a high level of self-efficacy has a lot of benefits for adults and their well being. People with high perceived self-efficacy are more likely to show positive results both physically and mentally. Individuals express better health condition and less psychological symptoms such as depression, stress and fatigue. They 
can also recover better and more rapidly from illness and injury compared with people with low self-efficacy (Bandura, 1992; Gecas; 1989; Grembowski et al., 1993).

Mental Health. Depression and anxiety have been the most predominant symptoms of mental health problems in our society. The research has conducted that mental health problems could emaciate one's functioning, creating a social burden for family and society (Bromberger \& Costello, 1992; Cheung \& Sun, 2000).

In Hong Kong, research by Cheung and Sun (2000) studied the relations between changes in self-efficacy and mental health. The survey used questionnaires to access 83 randomly selected members who worked in mutual-aid organization. The researchers used three different questionnaires including the Chinese General Health Questionnaire, Chinese State-Anxiety Inventory, and Centre for Epidemiologic Studies Depression Scale. The overall response rate was at $69 \%$. The results showed that self-efficacy was the key source of mediation for mental health. Specifically, when the participants had enhanced their self-efficacy at an earlier time, the mental health condition improved one month later.

Many researchers have examined the relationship between self-efficacy and depression since Bandura (1977) introduced the concept of self-efficacy. Maciejewski, Prigerson and Mazure (2000) studied the effects of symptoms of depression and stressful life events on self-efficacy.

The researchers randomly selected participants based on their zip code using multi-stage sample design at the age of 25 and over. This survey was designed as a longitudinal study with a baseline in 1986 (Wave I) and a follow-up survey in 1989 (Wave II). A total of 3,617 people were randomly selected. This survey was also 
designed for the interviewer to visit each household to find out the participants' depression, self-efficacy and stressful events. The overall response rate was at $83 \%$. Based on the results, a higher level of self-efficacy provided less severe symptoms of depression and less stressful life events. Therefore, sustaining a sense of control over one's life and environment might help to establish a certain degree of resistance to symptoms of depression shortly afterwards.

Physical Health. Self-efficacy has important theoretical and practical applications for health promotion and disease prevention among older adults. In performing specific health behavior, people with high self-efficacy are more likely to maintain protective stop behaviors (Cigarette smoking), control behaviors (weight control and diet), and health behaviors (exercise).

First of all, self-efficacy in the areas of stopping smoking has been continuously studied. Even if the smoking rate has significantly decreased in a decade, more than one in five Americans smoke. Approximately 21 percent of adults and about 22 percent of high school students continue to smoke in spite of intensive public health education. Therefore, smoking is the main cause of premature death in the U.S (Center for Disease Control, 2006).

Kowalski (1997) studied the important role of self efficacy and the smoking cessation process. The study was conducted in the state of Texas and a total of 75 subjects participated in this study. They were adult smokers who had smoked more than 10 cigarettes per day for over one year. They participated in one of 10 different smoking cessation programs. The researcher found 33\% of participants stopped smoking after 
finishing the smoking cessation program, but two-thirds of participants showed unsuccessful results.

The researcher also found that the success in smoking cessation was closely related with an individual's level of self-efficacy. As a result, a high level of self-efficacy can generate motivation, energy, and commitment for changing participants' smoking habit.

Second, there are many research results that with weights control, self-efficacy plays an important role. Chambliss and Murray (1979) conducted a study comparing a self-efficacy treatment group and a control group to compare cross-sectional evidence. Results from the study indicated that the self-efficacy enhancing treatment group had significantly greater weight loss when compared with the control group.

Queensland University of Technology nursing team (2008) examined women's weight loss and self-efficacy. The sample of 560 South-East Queensland women aged from 51 to 66. More than 60 percent of participants were overweight or obese. From the result, self-efficacy had emerged as a strong influence on women's decisions to do more exercise or eat more healthily. Results from the study indicated that a high level of selfefficacy lead them to eat healthily for any occasion such as being bored, upset, tired, on holiday or at a party.

\section{Exercise and Self-Efficacy}

Higher self efficacy on physical activity patterns among older and young people consistently influenced confidence in ones ability to engage in regular physical activity, enjoyment of physical activity and positive beliefs regarding the benefits of physical activity and overcome from barriers to being physically active (Center for Disease 
Control, 1999). Research suggested that self-efficacy expectancy, outcome expectancy, and outcome value are important in the initiation and maintenance of a variety of exercise programs (Brawley \& Rogers, 1993)

Grembowski et al. (1993) remarked when older adults' perceptions of their ability to perform health behaviors were higher than other adults; they showed more success in changing health behavior to reduce their risk of illness or mortality.

The relationship between physical activity and self-efficacy has shown very positive results from an accumulation of evidence recently. Numerous studies have found Albert Bandura's (1977 and 1997) social cognitive theory of self-efficacy to be particularly useful in explaining physical exercise behavior among older adults in the United States.

McAuley and his colleagues have studied extensively and added to our current understanding of exercise and self-efficacy relationships (McAuley, Mihalko, \& Bane, 1997; McAuley, et al, 2005) in the context of cross-sectional samples between exercise and self-efficacy. For instance, McAuley et al. (1997) examined self-efficacy and exercise among sedentary middle-aged(M=54.5 years) males $(N=56)$ and females $(N=58)$ and they tested sedentary middle aged in exercise during the previous 6 months using Rosenberg's Global Self-Efficacy Scale and Physical Self-Perception Profile(PSPP). From the result, self-efficacy had a significant relationship with the perception of physical condition $(\beta=.21, p<.05)$ and attractive body $(\beta=.61, p<.0001)$. Moreover, the perception of physical condition and attractive body were significantly related with physical self-worth ( $r$ 's $=.64$ and $.71, p<.0001$, respectively). 
In a more recent study of the relationship between self-efficacy and exercise of older adults, McAuley et al. (2005) examined these relationships using 4 measurement scales including Rosenberg Self-Efficacy Scale (RSE), Fox and Corbin's Physical SelfPerception Profile (PSPP), Exercise Self-Efficacy Scale (EXSEM) and the Physical Activity Scale for the Elderly (PASE) to a total of 174 older adults at the 1 and 5 year longitudinal assessments. From the results, self-efficacy remained significantly correlated with physical condition, attractive body, and strength sub domain-level efficacy variables such as physical self-worth on global self-efficacy at year 1.

Perkins, Multhaup, Perkins, and Barton (2008) studied self-efficacy and participating in physical and social activity of older adults in Spain and the United States. They found that there was a significant relationship between self-efficacy and participating in activity. Specifically, physical activity self-efficacy had the effects of increasing participation in physical activity for older adults in both Spain $(\beta=.391)$ and the United States $(\beta=.486)$ and also social activity self-efficacy had the effects of increasing participation in physical activity for older adults in both Spain $(\beta=.464)$ and the United States $(\beta=.386)$.

Many studies showed that self-efficacy significantly related with weight lost or weight control. First, Glynn and Ruderman (1986) tested the relationship between selfefficacy and weight control using Eating Self-Efficacy Scale (ESES) and found that there was a significant relation to weight losses of those who participated in weight loss program by using ESES. Sallit, Ciccazzo, and Dixon (2009) also examined the effects of a weight control program on eating behaviors of 216 female groups from July 2005 to June 2006. From the results, weight control group showed a $14 \%$ increase $(p<0.001)$ in 
their self-efficacy level for weight control which means that they had confidence in losing a certain amount of weight $(\mathrm{r}=0.582, \mathrm{p}<0.001)$ and the maintenance of that weight loss.

Moreover, Kaphingst et al. (2007) examined the relationship between physical activity and weight control among YMCA members of an urban area. Participants were randomly selected from 135 members. From the study results, more than $90 \%$ of members participated physical activity program and around $20 \%$ of members met fruit and vegetable consumption recommendations. Most participants showed high levels of self-efficacy to change their behaviors.

Higher levels of self-efficacy have been related with greater life satisfaction. Pang, Eng and Miller (2007) examined the mediating effects of psychological variables on the relationship between physical activity and global quality of life or satisfaction with life in older adults during the four year period. A sample of 174 older adults participated in this study. They were contacted at one year after entry into the program and then four years later. Most of them were sedentary people which means no regular physical activity on a daily bases.

The study showed that physical activity was significantly related to self-efficacy. Moreover, self-efficacy was significantly related to satisfaction with life, which means that participants who engaged in more physical activity, showed a higher level of selfefficacy. At the five-year assessment, the results indicated that physical activity over time was related with greater improvement in satisfaction. 


\section{Adult learning on Self-Efficacy}

Bandura (1994) and Semmar (2006) explained that people with a lower sense of self-efficacy may more easily fail when they start a new field of adult learning, or when they register in certain distance-learning programs. Moreover, a lower sense of efficacy may not only restrict adult activity ranges, but they have an inclination to weaken those that they participated in a certain activities.

In recent years, the relationship between self-efficacy and adult education has shown very positive results from an accumulation of evidence. Now more than ever before, researchers have the evidence to very precisely state that strong self efficacy enhances the academic success and goal setting in adult education (Lent, Brown, \& Larken, 1987; Semmar, 2006; West, Welch, \& Thorn, 2001).

In 2000 the National Center for the Study of Adult Learning and Literacy (NCSALL) reported on self-efficacy and adult persistence in their education. Self efficacy or self-confidence was a general feeling of being able to successfully learn and complete most tasks. The researchers suggested that adult educators should provide many experiences to achieve learners' goals through sustained efforts and offered role models for indirect teaching of their behaviors. Furthermore, the adult educators not only provided social supports including family, friends, staff and counselors to reinforce selfefficacy, but tried to help reduce the negative emotional circumstances such as tension, stress and depression (Comings, Parrella \& Soricone, 2000).

Other researchers have examined self efficacy and preparing for a vocation. The results showed that when adult learners have higher self-efficacy to accomplish their educational and vocational requirements, they concentrated on job searching and 
prepared themselves for various occupational roles. Moreover, they have more chances to select from a variety of career options (Semmar, 2006).

Zeldin and Pajares (2000) studied the personal stories of women who had high levels skills in areas of mathematics, science, and technology to better understand the way in which their self-efficacy beliefs influenced their academic and career choices. The researchers conducted Qualitative research with 15 participants. The researchers used semi-structured interviews and took around 60 minutes for each participant.

During the interview, the researcher found that the interviewees overcome many difficulties in their academic and career histories by their strong self-efficacy beliefs. Suzanne indicated how she overcome her financial obstacles

"I told (my father) I was going to college. Well, (the family) didn't have any money at all. He said, only rich men's children go to college. You can't go to college. And I was really shocked that he would say that. I said I will. And that's it. I got a scholarship and went. Never a doubt in my mind that I was going to college."

Moreover, the researchers also found that self-efficacy beliefs may be stronger for women in male-oriented careers than for operating in traditional settings.

\section{Summary}

Self-efficacy is a person's belief in his or her ability to succeed in a particular situation (Bandura, 1977 and 1999). These beliefs are made from a person's feeling, thought, motivation and conduct. A strong sense of efficacy reinforces personal attainment and human well-being in various ways. People with full confidence can 
manage the exceptionally difficult tasks with surprising capabilities rather than give up their tasks.

Several studies found that a high level of self-efficacy has a lot of benefits for adults and their well being (Magaletta \& Oliver, 1999). People with high perceived selfefficacy are more likely to show positive results both physically and mentally. They show better health condition and less psychological symptoms such as depression, stress or fatigue (Weber et al., 2003). They can also recover better and more rapidly from illness and injury compared to people with low self-efficacy (Bandura, 1992; Gecas; 1989, Grembowski, et al., 1993).

Self-efficacy has important theoretical and practical applications for health promotion and disease prevention among older adults. In performing specific health behavior, people with high self-efficacy are more likely to develop stop behaviors cigarette smoking control behaviors- weight control and diet, and health behaviorsexercise (Dino, Kamal, Horn, Kalsekar, \& Fernandes, 2004).

Now more than ever before, researchers have the evidence to very precisely state that strong self-efficacy enhances the academic success and goal setting in adult education. Self-efficacy or self-confidence is a general feeling of being able to successfully learn and complete most tasks (Lent, Brown, \& Larken, 1987; Semmar, 2006; West, Welch, \& Thorn, 2001). 


\section{CHAPTER III}

\section{METHODOLOGY}

\section{Introduction}

This study was conducted in the Muncie/Delaware County community, during the spring and summer of 2010. It was designed to determine the relationship between SelfEfficacy and the level of physical activity of older adults. The demographics categories included gender, marital status, years of completed education, and levels of income. This chapter provides information concerning the choice of participants, the instrumentation used, procedures used in the study, the design of the study, and the analysis of the data.

Older adults are at higher risk of chronic disease and conditions such as Alzheimer's disease, arthritis, depression, psychiatric disorders, and osteoporosis (CDC, 2008). Physical activity and its relationship to Self-Efficacy in older adults were key measurements in this study.

In the United States, adults over 65 years of age are most frequently used to describe eligibility for benefits available to them, for example, Medicare and pensions. In this study, "older adult" refers to a person 50 years of age or older, a necessity based on the availability of participants. This is in line with the definition provided by the Center for Disease Control and Prevention (CDC, 2008).

The majority of people at the selected sites for recruitment of participants, the Community Center for Vital Aging (CCVA), Forest Park Senior Center (FPSC), and the Retired Senior Volunteer Program (RSVP) are age over 50, and are also actively involved in programs that include some form of physical activity. 


\section{Participants}

When collecting people for my study, the participants included both men and women 50 years of age and older. They participated in one of three programs located in the Muncie, Indiana, Delaware County areas: The Community Center for Vital Aging (CCVA), Forest Park Senior Center (FPSC), and Retired Senior Volunteer Program (RSVP). A total of 202 questionnaires were distributed to randomly selected participants in these three programs and 124 were returned, a $61.39 \%$ return rate.

Procedures from Institutional Review Board (IRB) Approval and Informed Consent: Protection of Human Subjects

First, the Institutional Review Board (IRB) reviewed the initial questionnaire along with the cover letter to be given to the participants and returned them with suggestions in December of 2009 (See Appendix A). The second step determined the primary locations for the distribution and collection of the questionnaires and cover letters. The three agencies noted above agreed to supply participants. Third, with the sites identified, the three coordinators granted permission for the study to be conducted in their agencies. The coordinators are Judy Elton at CCVA, Bruce Reynolds at FPSC and Neal Miller at RSVP.

At the CCVA and FPSC facilities, the participants received packets that included both the questionnaires and the cover letter. The cover letter stated clearly that (1) participation was voluntary, (2) the information would be anonymous, and (3) participants could withdrawal at any time and for any reason, and also it was included an informed consent form (See Appendix B). All the participants signed and returned the consent form. 
The participants returned the questionnaires at the end of the program, either by site collection or through the mail. The results were placed into a data base by the researcher. Confidentiality was protected throughout the process. Data was reported only in the aggregate.

\section{Selecting of Participants}

After the IRB approval the study, and the agency coordinators, upon request, gave their approval for the participation of their agency in the study (CCVA; FPSC; RSVP), testing times and locations were then set and announced.

1. The Community Center for Vital Aging (CCVA)

The mission of CCVA is "to enhance the lives of older adults in the Muncie/Delaware County Community through creative, cultural, and intergenerational programs that promote wellness throughout the lifespan."

CCVA opened in May of 2001 and now offers a variety of programs. It is an important resource for analysis focused on the aging process because it offers programs tailored for community members fifty years of age and older.

Judy Elton, the program coordinator of CCVA at Ball State University approved the inclusion of the agency in the study. After receiving the letter of agreement (See Appendix C), the collection of data took place from March 30, 2010, through July 2 , 2010. Participants were limited to people who regularly participated in activity programs, such as walking, tai-chi, yoga and related health activities.

Of the nineteen people who participated in the brain health seminar at CCVA, twelve returned their questionnaires. The instructors of exercise programs also distributed the questionnaires to the yoga and tai-chi exercise groups. Of the 40 people who actively 
participated in this exercise program, 19 returned the questionnaires in the spring and summer semesters. Seven people actively participated in the walking club and all seven returned the questionnaires. Two students and two instructors in a computer class, "How to burn a CD," filled out and returned questionnaires. The final results: of the 80 questionnaires distributed to people in these five distinct programs offered at CCVA, 45 returned them, giving a $56.25 \%$ level of return.

\section{1-1. Outreach programs}

As part of the CCVA mission, an outreach program is offered. The mission of the outreach program is "to reach older adults in the Delaware County area that may not be able to attend programs at the Community Center for Vital Aging. We strive to tailor programs to each individual facility. We strive to focus on the seven dimensions of wellness and to target specific health concerns, physical activity, arts and crafts, music therapy, computer training, cultural presentations, and mental exercises.”

During the spring of 2010, the outreach team visited five sites: Snap-2-It (a predominantly African-American womens fitness group), Wilson School Apartments (a low-income housing complex), Ashgrove Crossing (a low-income senior housing complex), Golden Living (a long term care facility that specializes in Alzheimer's care) and Alpha Center (an adult day stay facility). Of these five agencies and living units, two programs participated in the study, the Snap-2-It program and Ashgrove Crossing. Of the twenty-eight people who received the questionnaires, twenty-two completed and returned them $(78.57 \%)$. 


\section{Forest Park Senior Center (FPSC)}

The mission of Forest Park Senior Center is "to improve the quality of life for all persons aged over 55 in Muncie/ Delaware County and/or surrounding areas by providing them with educational, recreational, health and social activities and services. This agency caters to middle-class to poverty level seniors in the areas of education, recreation, and wellness." It offers a variety of programs such as line dancing, Bluegrass jam sessions, the card game Euchre, a Bible Study class, and several exercise classes.

On April 15, 2010, Bruce Reynolds, director of the Forest Park Senior Center, approved participation by select members (See Appendix D). On April 20, 2010, I visited the FPSC and joined the Euchre game, a traditional Indiana card game. I read and explained that participation in the study was voluntary and that no names would be collected. I stressed that participants would be able to withdraw from the study at any time and for any reason. Sixteen people actively participated in the card game and 5 retuned the questionnaires. Participants completed the questionnaires and returned them either at the end of the session or in the mail.

On April 27, 2010, during lunch, I explained the study to the lunch group. I distributed 30 questionnaires and had 17 returns. One participant was eliminated because of age and participants on two forms failed to complete section 3, the Exercise SelfEfficacy scale. For purposes of data collection, these questionnaires were not included.

Another visit to the FPSC was made on June 8, 2010. Five people in a yoga class and eight members of the line dancing class (out of twenty-five members) filled out and returned the questionnaires. The FPSC returned 39 of the 92 questionnaires distributed, a $48.75 \%$ return rate (See Table 1$)$. 


\section{Retired Senior Volunteer Program (RSVP)}

The RSVP “is America’s largest volunteer network for people age 55 and older. Join RSVP and you will be joining nearly 500,000 volunteers across the country who are tackling tough issues in their communities. You've gained a lifetime of experience and knowledge. Now is the time to put your skills and talents to work by volunteering with RSVP".

On June $5^{\text {th }}, 2010$, I contacted Neal Miller, the program coordinator of RSVP and received permission to include participants at his agency (See Appendix E). Participants were chosen at random from a database made available by the Retired and Senior Volunteer Program. I contacted eleven participants out of 175 to determine if they wanted to participate in the study and 6 either replied and/or agreed to participation. I explained the parameters of the research by phone and emphasized that it was voluntary. I mailed six questionnaires and the participants returned six questionnaires. The total return rate was $100.00 \%$ (See Table 1$)$.

4. Friends and family

Some participants were willing to ask friends and families to fill out the questionnaire. Those questionnaires are treated the same as those completed at the agencies. Eight people received the questionnaires and eight completed and returned to the researcher $(100.00 \%)$.

In summary, of those who participated, the response rate for the CCVA sample was 45 of $80(56.25 \%)$, the outreach program sample was 22 of $28(78.57 \%)$, the Forest Park Senior Center sample was 39 of 80 (48.75\%), the RSVP sample was 6 of 6 $(100.00 \%)$, and the family and friends sample was 8 of $8(100.00 \%)$. Of the two hundred 
and two questionnaires distributed to people in these five programs, 124 returned the questionnaires, giving a $61.39 \%$ level of returns.

Table 1

Participants

\begin{tabular}{|c|c|c|c|}
\hline CCVA & $\begin{array}{l}\text { Numbers of } \\
\text { distribution }\end{array}$ & Numbers of return & Percentage (\%) \\
\hline Walking club-summer & 7 & 7 & 100.00 \\
\hline Yoga and tai-chi & 40 & 19 & 47.50 \\
\hline $\begin{array}{l}\text { The other white Meat: } \\
\text { Misunderstood Pork }\end{array}$ & 10 & 3 & 33.33 \\
\hline Brain Health & 19 & 12 & 63.16 \\
\hline Computer Class & 4 & 4 & 100.00 \\
\hline Total & 80 & 45 & 56.25 \\
\hline FPSC & $\begin{array}{l}\text { Numbers of } \\
\text { distribution }\end{array}$ & Numbers of return & Percentage $(\%)$ \\
\hline Line dance & 25 & 8 & 32.00 \\
\hline Euchre-Card Game & 16 & 5 & 31.25 \\
\hline Yoga & 5 & 5 & 100.00 \\
\hline LifeStream Lunch & 30 & 17 & 56.67 \\
\hline Volunteers & 4 & 4 & 100.00 \\
\hline Total & 80 & 39 & 48.75 \\
\hline RSVP & $\begin{array}{l}\text { Numbers of } \\
\text { distribution }\end{array}$ & Numbers of return & Percentage (\%) \\
\hline Volunteers & 6 & 6 & 100.00 \\
\hline Total & 6 & 6 & 100.00 \\
\hline Site Visit & $\begin{array}{l}\text { Numbers of } \\
\text { distribution }\end{array}$ & Numbers of return & Percentage (\%) \\
\hline Snap-2-it & 20 & 18 & 90.00 \\
\hline Ashgrove Crossing & 8 & 4 & 50.00 \\
\hline Total & 28 & 22 & 78.57 \\
\hline Others & $\begin{array}{l}\text { Numbers of } \\
\text { distribution }\end{array}$ & Numbers of return & Percentage $(\%)$ \\
\hline Friends and Family & 8 & 8 & 100.00 \\
\hline Total & 8 & 8 & 100.00 \\
\hline Total Response & 202 & 124 & 61.39 \\
\hline
\end{tabular}




\section{Instrumentation}

The questionnaires completed by the participants measured demographic information, physical activity and physical activity Self-Efficacy.

\section{Demographic Information}

The questionnaire, using five questions, asked each participant to provide demographic information concerning age, gender, marital status, level of education and household income (See Appendix F).

The Habitual Physical Activity Index (HPAI).

The Habitual Physical Activity Index (HPAI) provides data concerning the level of physical activity for older adults. The HPAI is designed to help determine the time older adults typically spend in physical activity (See Appendix G). Participants completed a self-administered 30-item questionnaire. The questions asked for three primary types of information: (1) Household and Family Care Activities, (2) Occupational Activities and (3) Leisure Activities.

The original version was developed by Baecke, Burema, \& Frijters (1982) in the field of physical activity assessment. The Habitual Physical Activity (HPA) was designed as a self-administered 16-item questionnaire with three subscales, namely Work, Sport, and Leisure-time. The HPA was commonly used to measure habitual physical activity in healthy adults and was to establish meaningful indices of physical activity.

All items applied a 5 point self-report format ranging from the lease frequently engaged in activities depicted as "never" to the most frequently engaged in activities depicted as "always" from 1 to 5 , with 1 being "never" and 5 being "always". A sixteenitem questionnaire included eight items relating to Work, and four items relating to Sport 
and four items relating to Leisure. Test-retest stability of the Work index exceeded* .88 , the Sport Index exceeded* .81, the Leisure index also exceed*.74, respectively (Baecke, Burema, \& Frijters, 1982).

Burns and Froman modified the HPAI in 1997. This version was designed as a self-administered 30-item questionnaire with five subscales: Occupation, Movement, Sports, Leisure-time and Sleep. The researchers distributed it in the United States and examined whether the HPAI was adaptable to and valid for use with both healthy people and people with cardiac disease. A random sample of 213 cardiac patients participated.

Generalizablility of coefficients in the Occupational and Leisure-time categories suggested that the absolute reliability coefficients of the subscales were .76 and .72, respectively. The relative reliability measures for the Occupation and Leisure-time indexes, however, were more acceptable at .82 and .77 . Thus, the scales were more coherent when used to assess the rank order of individuals on the physical activity index (Burns and Froman, 1997)

A few studies draw on data generated by the HPAI and the majority of its users believe it is an accurate measuring tool. The most common use of the HPAI is the measure of habitual physical activity in healthy adults, including but not limited to light physical activity (Burns and Froman, 1997, Gleeson-Krieg, 2004).

The current data of the Habitual Physical Activity Index (HPAI) was obtained using a 30-item questionnaire with three sections: (1) Household and Family Care Activities, (2) Occupational Activities and (3) Leisure Activities. Respondents reported on the kinds of physical activities they had done in the past month. The Household and Family Care index contained 11 items. The first three questions (Question 1 to 3) ask 
about child care for children of less than 2 years of age, of children between 2 and 5 years of age and either a disabled child or elderly person. The three indexes are scored on a 1 to 5 scale with higher scores indicating a higher level of physical activity.

Questions 4 through 11 focus on house cleaning, yard work and home decoration. The eight items are scored on a one to five scale with higher scores indicating a higher level of physical activity. The total scores of questions four through eleven in conjunction with the family care index score of the first three questions are summed and then divided by eleven to find an average score.

The Occupational Index contains eight items. The first two questions ask about the respondent's occupation and the number of hours worked in a week. The occupation question is divided into three levels, low, medium and high, based on guidelines created by Baecke, Burema, \& Frijters (1982). The lower level of occupation includes, but is not limited to, jobs that require the least amount of physical activity: clerical work, driving, retail, teaching, studying, medical practice, and occupations that require a university education. This is scored as a 1 . The middle level of occupation includes jobs with moderate physical activity: factory work, plumbing, carpentry, and farming. It is scored as a 3. The high level of occupation consists of jobs that require a high degree of physical activity such as dock work and construction work. It is scored as a 5 .

The remaining seven questions in the occupational index are related to the level of physical activity used while working. Answers use a 5-point self-report format ranging from those least engaged in physical activities, described as "never", to those most frequently engaged in physical activities, described as "always" or "much heavier". The total scores of the occupational index are added together and then divided by eight to find 
an average score. However, questions 13 and 19 had an inverse form, and were put into to the data as reverse-scored before applying statistical analysis.

The Leisure Index contains eleven questions. This section addresses the respondents' participation in various activities and provides summary questions with scores ranging from 1 for "never" to 5 for "always". In addition, some items require specification of the subject's occupation and the types of physical activity entered into. The Occupational and Leisure Index questions also receive scores ranging from a low of one to a high of five. To find the average score, the total scores of the leisure activity questions are added and then divided by eleven.

The scores are able to define the level of physical activity of the participants. From the total score of the HPAI, the physical activity of the participants is determined by the total score for the 3 indexes obtained by adding together the 3 indexes. The three indexes (Household and Family Care Activities, Occupational Activities, and Leisure Activities) provide a total score by summing the three indexes. The possible score ranged from 3 (the lowest score) to 15 (the highest score).

Participants were divided into two groups based upon their scores in Leisure Activities. If participants have scored less than an average of 3.00, they were considered "sedentary" group. If participants have scored more than an average of 3.00, they were considered "moderate or regular physical activity" group. Sedentary classification respondents are not meeting the Surgeon General's recommendation of "at least 30 minutes of endurance-type physical activity, of at least moderate intensity, on most days of the week" (Public Health Service, 1996, p. 28). 


\section{Exercise Self-Efficacy Scale (ESES)}

To examine the perceived Self-Efficacy of older adults, the study employed the Exercise Self-Efficacy Scale (ESES). The ESES was developed by Bandura (2006) as a simple method to measure Self-Efficacy beliefs through exercise. It is a self-administered 18-item questionnaire (See Appendix H).

The respondents mark each question to delineate different levels of Self-Efficacy, and they base their score on the strength of their belief in their ability to complete the requisite activities. Respondents rated their Self-Efficacy beliefs on a 100-point scale, based on 10-unit intervals from 0 (cannot do at all); through a middle degree of assurance, 50 (moderately certain can do); to complete assurance, 100 (highly certain can do) (Bandura, 2006).

In the present study, the ESES was used to examine the respondent's own SelfEfficacy level and to use that level to promote regular exercise. Each respondent judges how well he/she regularly exercises and identifies barriers to regular exercise. Examples of such barriers include being tired or depressed, a sense of being under pressure at work, bad weather, or when other commitments or more interesting things to do are available. Unfortunately, there is no reliability and/or validity information for the ESES, however, Bandura examined task-efficacy with the Exercise Self-Efficacy Scale in accordance with social cognitive theory. The items specifically focused on exercise program maintenance areas. The author emphasized the significance of the face validity of the survey because the validity can promise the accurate answer from a respondent about his/her perception toward ability of exercise engagement within specific conditions (Gilinsky, 2010). 
The degree of confidence determined by recording a number from 0 to 100 is a stronger predictor of performance than that with a range of 1 to 5 . A small range scale is less sensitive as well as less reliable in identifying specific characteristics. One reason for this is that respondents normally avoid the high point so the actual range available for use is only two or three points. A small range scale also loses differentiating information because it is unable to perceive differences in the same answers (Pajares, Hartley, \& Valiante, 2001).

\section{Data Analysis}

The Statistical Package for the Social Science (SPSS 18.0) was the analysis tool for the data. The demographic variables of age, gender, marital status, level of education and income levels were evaluated using descriptive statistics. The sample age and income levels were coded in a continuous format, whereas gender, marital status, and education were represented with categorical variables $(1=$ Male, $2=$ Female $)$ and $(1=$ Single, $2=$ Married $)$, and $(1=$ Elementary, $2=$ Middle School, $3=$ High School, $4=$ College and $5=$ Graduate).

The first question examined the relationship between exercise self-efficacy and level of physical activity among older adults. The hypothesis anticipated that people with a higher level of physical activity are more likely to have higher self-efficacy for physical activity. One-way analysis of variance (ANOVA) was performed in order to access the relationship between the Habitual Physical Activity Index (HPAI) and the Exercise SelfEfficacy Scale (ESES). The Habitual Physical Activity index was divided into three subscales: Household and Family Care, Occupational, and Leisure Activities. The hypothesis required analysis of each sub-group and the relationship each group had to the others. 
The second question examined the relationship between self-efficacy for exercise and the level of physical activity through various demographic dimensions including age, gender, marital status, years of completed education, and household income. Multiple regression analysis was conducted on the three sub-groups of the Habitual Physical Activity Index (HPAI). Age, gender, marital status, education, and income formed a combined predictor independent variables. The Exercise Self-Efficacy Scale (ESES) formed the dependent variable. This analysis examined many variables at the same time. 


\section{CHAPTER 4}

\section{RESULTS}

\section{Purpose of the Study}

The purpose of this study was to examine the relationship between self-efficacy for exercise and the level of physical activity for older adults. A secondary purpose was to analyze if differences existed between self-efficacy and the level of physical activity through various demographic dimensions including gender, years of education, and income. It was hypothesized that (1) people with a higher level of physical activity are more likely to have higher self-efficacy for physical activity and (2) people with high level of education and income are more likely to have higher self-efficacy for physical activity.

Participants in the study, drawn from the Muncie, Delaware County community in Indiana, completed and returned the questionnaires for the study during the spring and summer of 2010. Two local senior centers and one volunteer group provided the participants. At the Community Center for Vital Aging, 75 older adults participated and at Forest Park Senior Center, 39 older adult, enrolled in various programs participated. At the Retired Senior Volunteer Program Last, 6 older adults participated. At the CCVA the final response rate was 75 of $116(64.66 \%)$, at FPSC, 39 of $80(48.75 \%)$ and at RSVP 6

of $6(100.00 \%)$. The overall response rate for the three participating agencies was $61.39 \%$ (124 returned out of 202).

\section{Data Analysis}

The Statistical Package for the Social Science (SPSS 18.0) provided the analysis of the data. The input of the data took place from June 28, 2010 through July 8, 2010. 


\section{Descriptive of Sample}

\section{Demographic variable}

Table 2 details the demographic characteristics of the participants. Continuous variables were used to determine the age demographics. The youngest participant was 50 years of age and the oldest 90 years of age. The mean age of the participants was 69.3 years. The largest number of the participants $(\mathrm{N}=46,37.1 \%)$ fell between the ages of 60 years to 69 years old. The second largest group $(\mathrm{N}=41,33.1 \%)$ fell between the ages 70 years to 79 years old.

Distinctive categorical variables were used to describe the gender, marital status, years of completed education and household income level, of the participants. A large number of participants $(\mathrm{N}=97,78.2 \%)$ were females whereas the participation level of males was only $27(\mathrm{~N}=27,21.8 \%)$. In terms of marital status, sixty-two people $(50 \%)$ were married and sixty-two (50\%) single. This indicates that participants were divorced, never married, separated or widowed.

The largest number of participants $(\mathrm{N}=35,28.2 \%)$ reported an annual household income above $\$ 50,000$, and nineteen of participants $(\mathrm{N}=19,15.3 \%)$ reported an annual household income of between $\$ 35,000$ and $\$ 49,999$. 
Table 2

Demographic Characteristics of Participants $(N=124)$

\begin{tabular}{|c|c|c|}
\hline $\begin{array}{c}\text { Variables } \\
\text { Categorization }\end{array}$ & Frequency & Percentage $(\%)$ \\
\hline \multicolumn{3}{|l|}{ Age } \\
\hline $50-59$ & 18 & $14.5 \%$ \\
\hline $60-69$ & 46 & $37.1 \%$ \\
\hline $70-79$ & 41 & $33.1 \%$ \\
\hline $80-90$ & 19 & $15.3 \%$ \\
\hline \multicolumn{3}{|l|}{ Gender } \\
\hline Male & 27 & $21.8 \%$ \\
\hline Female & 97 & $78.2 \%$ \\
\hline \multicolumn{3}{|l|}{ Mrital Status } \\
\hline $\begin{array}{c}\text { Single } \\
\text { (Divorced, } \\
\text { Widowed) }\end{array}$ & 62 & $50.0 \%$ \\
\hline Married & 62 & $50.0 \%$ \\
\hline \multicolumn{3}{|l|}{ Educational Level } \\
\hline Elementary & 2 & $1.6 \%$ \\
\hline Middle & 7 & $5.6 \%$ \\
\hline High & 55 & $44.4 \%$ \\
\hline College & 24 & $19.4 \%$ \\
\hline Graduate & 36 & $29.0 \%$ \\
\hline \multicolumn{3}{|l|}{ Household Income } \\
\hline$<\$ 10,000$ & 16 & $12.9 \%$ \\
\hline $\begin{array}{c}\$ 10,000- \\
\$ 19,999\end{array}$ & 26 & $21.0 \%$ \\
\hline $\begin{array}{c}\$ 20,000- \\
\$ 34,999\end{array}$ & 28 & $22.6 \%$ \\
\hline $\begin{array}{c}\$ 35,000- \\
\$ 49,999\end{array}$ & 19 & $15.3 \%$ \\
\hline$\$ 50,000+$ & 35 & $28.2 \%$ \\
\hline
\end{tabular}


The completion of highest educational levels is as follows: $1.6 \%$ of the participants $(\mathrm{N}=2)$ had completed elementary school; $5.6 \%$ of the participants $(\mathrm{N}=7)$ had completed Middle school; $44.4 \%(\mathrm{~N}=55)$ had completed High school; $19.4 \%(\mathrm{~N}=$ 24) had completed undergraduate college educations; and $29.0 \%(\mathrm{~N}=36)$ had completed Graduate degrees, including both Masters and Doctoral degrees (See Figure 1). The most frequent level of education was the completion of a high school degree.

\section{Level of Education}

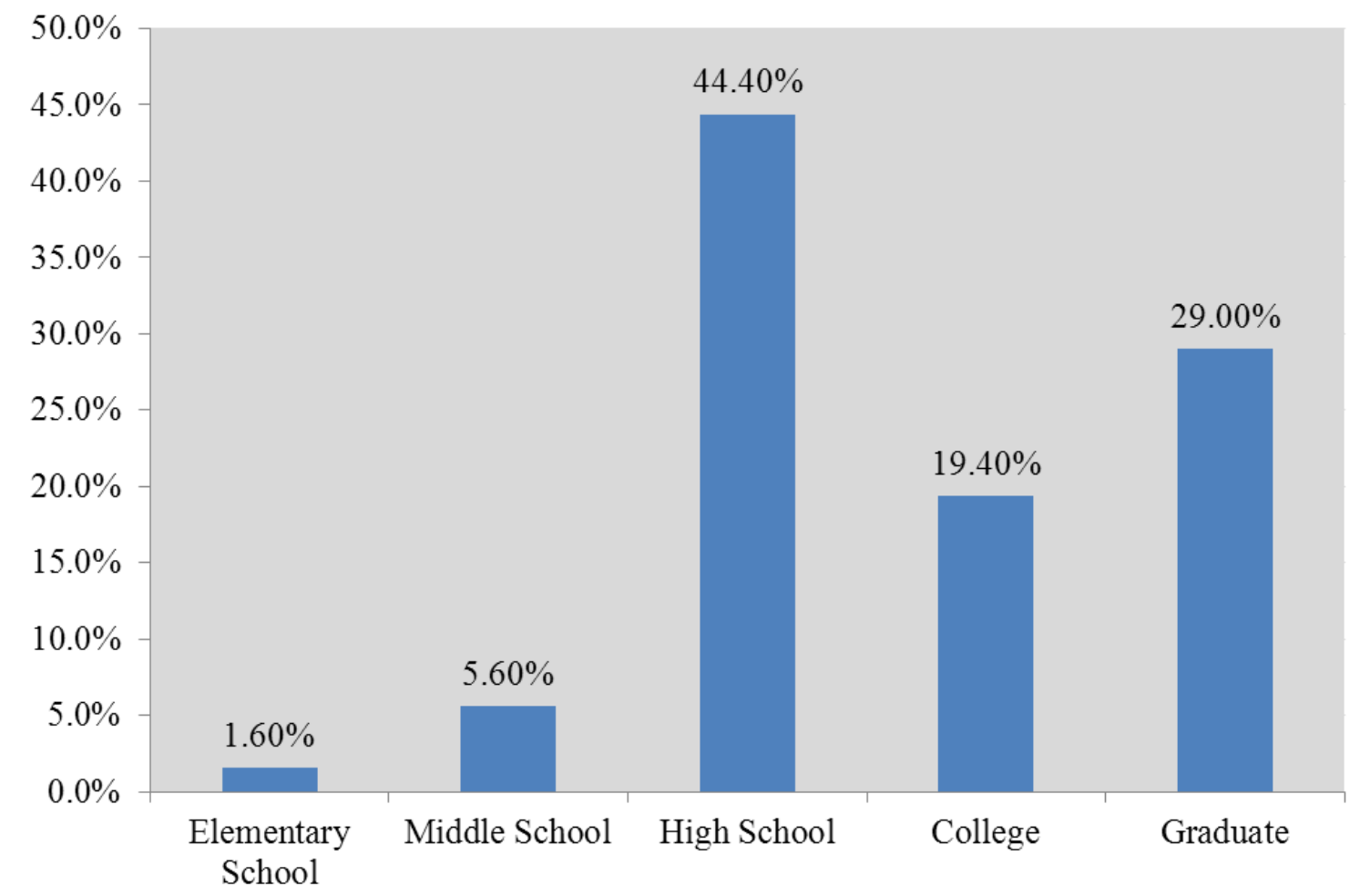

Figure 1. Response Percentage of Participants' Level of Education

Concerning the Household income level of the participants, $12.9 \%(\mathrm{~N}=16)$

reported an annual household income of less than $\$ 10,000 ; 21.0 \%(\mathrm{~N}=26)$ reported an annual household income of between $\$ 10,000$ and $\$ 19,999 ; 22.6 \%(\mathrm{~N}=28)$ reported an annual household income of between $\$ 20,000$ and $\$ 34,999 ; 15.3 \%(\mathrm{~N}=19)$ reported an annual household income of between $\$ 35,000$ and $\$ 49,999$; and $28.2 \%(\mathrm{~N}=35)$ reported 
an annual household income above $\$ 50,000$. These numbers indicate that more than $43 \%$ of the participants earned over $\$ 35,000$ per years (See Figure 2). Figure 2 indicates the highest level of income was is $\$ 50,000$. The mean income is $3.25(S D=1.40)$.

\section{Household Income}

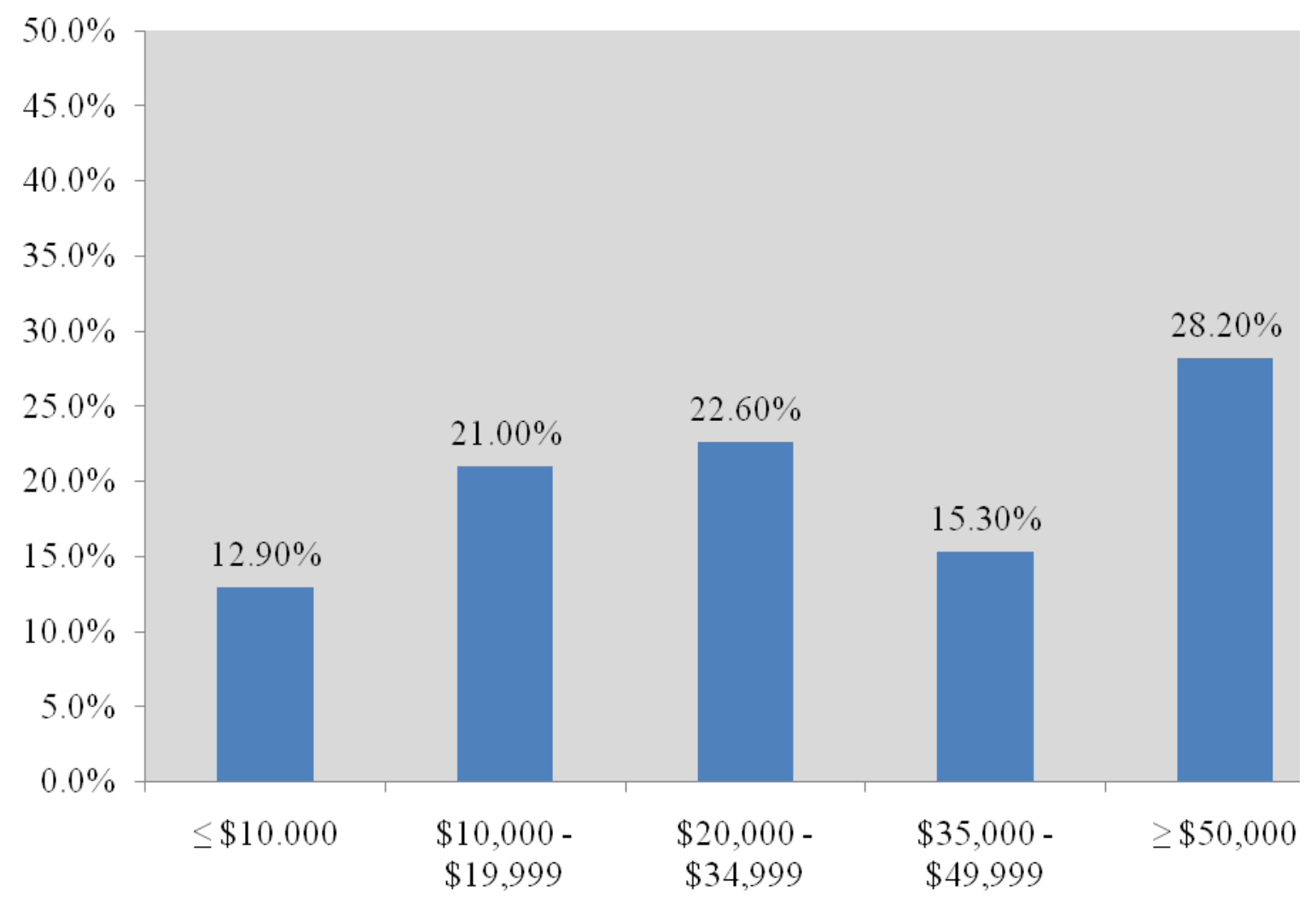

Figure 2. Response Percentage of Participants' Household Income

\section{Physical Activity}

The scores of the Habitual Physical Activity Index (HPAI) range from 1 to 5 with higher scores indicating a higher level of physical activity. The baseline of the entire sample $(\mathrm{N}=124)$ shows that least scores were 1.24 and the highest were 3.91 . The overall mean of HPAI is $1.89(S D=0.58)$.

The HPAI was designed to be self-administered. It consists of a 30-item questionnaire consisting of three sections; (1) household and family care activities, (2) 
occupational activities and (3) leisure activities. The total number of participants who responded to the household and family care activities was $124(M=2.13, S D=.527)$. The scores on the household and family care activities range from 1 to 5 . The lowest score was 1.00 and the highest 3.36 .

Thirty two of the participants $(26 \%)$ completed to questions concerning occupational activities, and 92 (74\%) people did not fill out this portion of the questionnaire, because the majorities were retired. Scores on the Occupational activity ranged from 1 to 5 . The lowest score was 2.29 and the highest was 3.71. $(M=2.94, S D=$ .39). The total numbers of participants responding to the leisure activities' questions were $124(M=2.44, S D=.798)$. Scores on the leisure activities ranged from 1 to 5 . The lowest scores were .44 and the highest 4.67. See Figure 3.

\section{Types of Physical Activities}

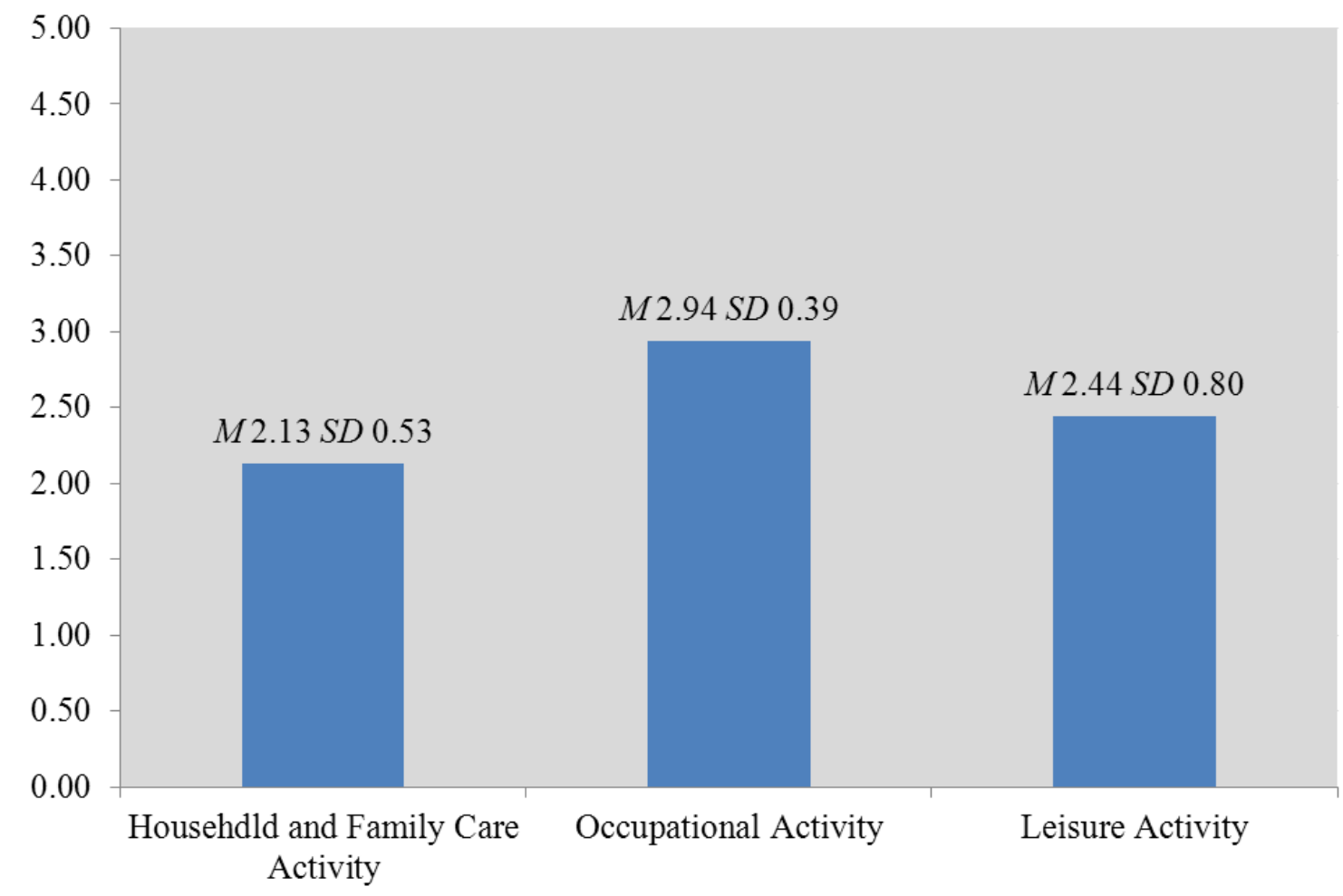

Figure 3. Response Rate of Physical Activities 


\section{Self-Efficacy}

The Exercise Self-Efficacy Scale (ESES) contained a self-administered 18-item questions and potential scores of each question had range from 0 to 100 , based on 10-unit intervals from 0 (cannot do at all); through a middle degree of assurance, 50 (moderately certain can do); to complete assurance, 100 with the highest scores indicating higher SelfEfficacy levels. In examination of the entire sample $(\mathrm{N}=124)$ at baseline, the minimum scores were 0.00 and the maximum 1800 . The summary of the Self-Efficacy scale indicates that the number of total response was $80(65 \%)$. And, the mean percentage of total response was $42.59(S D=27.57)$ per each item.

The first research question examined the relationship between self-efficacy and level of physical activity among older adults. The hypothesis anticipated that significant differences between levels of physical activity and exercise self-efficacy would be found. One-way analyses of variance (ANOVA) were performed in order to access the relationship between the Habitual Physical Activity Index (HPAI) and the Exercise SelfEfficacy Scale (ESES).

Data analysis included the use of one-way ANOVA to determine the relationship between the Habitual Physical Activity Index (HPAI) and the Exercise Self-Efficacy Scale (ESES). A total of 124 people participated. However, when the researcher performed a One-way ANOVA to assess the total mean of HPAI, SPSS recognized very small numbers $(\mathrm{N}=28)$ as the total participants in HPAI. The questions of the occupational section caused this limited response because most of the participants were retired. Therefore, there is limited of analysis between the total mean of Habitual Physical Activity Index (HPAI) and Exercise Self-Efficacy Scale (ESES). 
Therefore, HPAI was divided into three sub-groups: (1) household and family care, (2) occupational and (3) leisure activity. Each sub-group and its relationship to SelfEfficacy were determined using a One-Way ANOVA test.

First, in terms of the One-way ANOVA, Self-Efficacy was a dependent variable and the sub-group of household and family care activities was an independent variable. The category of Household and Family Care Activities were further divided into two groups: (1) the lower level of household and family care activity group (valid points were less than 3.00 and the cumulative percentage was $66.9 \%$ ) and (2) the high level of household and family care activity (valid points were more than 3.00 and the cumulative percentage was $33.1 \%)$.

The second test compared the dependent variable (Self-Efficacy) and independent variables (Occupational Activities). Occupational Activities were divided into three groups: no occupation (the valid point was 0 and the cumulative percentage was $74 \%$ ), less occupational activity (the valid point was less than 3.00 and the cumulative percentage was 13\%) and the active group (the valid point was more than 3.00 and the cumulative percentage was $13 \%)$.

The last test compared the Dependent variable (Self-Efficacy) and Independent variables (Leisure activities) using One-way ANOVA. Leisure activities were divided into two groups, a sedentary group (the valid point was less than 3.00 and the cumulative percentage was $76.4 \%$ ) and a moderate or regular exercise group (the valid point was more than 3.00 and the cumulative percentage was $23.6 \%$ ). The moderate exercise group indicated they were physically active "sometimes". 


\section{Data Analysis}

\section{One-Way ANOVA}

Table 3 presents the results of the main effect and the interaction effect determined by the One-Way ANOVA. The first dimension examined the Self-Efficacy and level of household and family care activity, both the lower level group $(M=39.11$, $S D=26.75)$ and the high level group $(M=49.55, S D=27.06)$. There were no significant differences between the two groups of household and family care $(F=3.51)$ on Selfefficacy scale scores. Even though, the results between the Self-Efficacy and level of household and family care activity was not a significant difference, the results yielding a p-value of .06 are considered on the borderline of a statistical significance. Therefore, it has a future investigation.

The second dimension examined the Self-Efficacy and occupational activity groups: no occupation activity $(M=39.75, S D=28.43)$, less occupational activity $(M=$ $47.90, S D=24.83)$ and an active group $(M=54.41, S D=20.42)$. There were no significant differences between three groups of occupational activity on Self-efficacy scale scores. $F=2.08$.

The third dimension examined the Self-Efficacy and leisure activity groups, a sedentary group and a moderate or regular exercise group. There were significant differences observed between leisure activity groups $(p<.001)$ including moderate exercise groups $(M=61.33, S D=26.24)$ and sedentary groups $(M=36.60, S D=24.60)$ on Self-efficacy scale scores (See Table 3). 
Table 3

The Result of One-Way ANOVA for Self-Efficacy and Level of Physical Activities.

\begin{tabular}{lccccc}
\hline \multicolumn{1}{c}{ Source } & $S S$ & $D f$ & $M S$ & $F$ & $P$ \\
\hline $\begin{array}{l}\text { Household and } \\
\text { family care }\end{array}$ & 2533.67 & 1 & 2533.67 & 3.51 & 0.06 \\
$\begin{array}{l}\text { Occupational } \\
\text { activities }\end{array}$ & 3013.84 & 2 & 1506.92 & 2.08 & 0.13 \\
Leisure activities & 11679.99 & 1 & 11676.99 & 18.64 & $0.001^{* *}$ \\
Error & 60162.97 & 98 & 626.70 & & \\
\hline Total & 71842.96 & 97 & & & \\
\hline
\end{tabular}

Note. ${ }^{*} p<.05,{ }^{* *} p<.01$

Levene's Test of Equality of Error Variances was used to find out the assumption that the error variance of the dependent variable (Self-Efficacy) and independent variables including level of Household and Family Care Activities (i.e., Low vs. High), level of Occupational Activities (i.e., No, Less Activity, and Active Group) and level of Leisure Activities (i.e., Sedentary vs. Moderate). The results for Leven's Test of Equality of Error Variances are indicated in Table 4 and show that the error variance of the dependent variable was equal across the groups.

The results show that there is no difference of equality of error variances between Self-Efficacy and the three groups including level of Household and Family Care Activities $(F=.001, p=\mathrm{n} . \mathrm{s})$, level of Occupational activities $(F=2.96, p=\mathrm{n} . \mathrm{s})$ and level of Leisure Activities $(F=.25, p=$ n.s). 
Table 4

Levene's Test of Equality of Error Variances

\begin{tabular}{lcccc}
\hline $\begin{array}{l}\text { Dependent Variable: Self- } \\
\text { Efficacy }\end{array}$ & F & df1 & df2 & Sig. \\
\hline $\begin{array}{l}\text { Level of household and } \\
\text { family care activities }\end{array}$ & 0.00 & 1 & 96 & 0.98 \\
$\begin{array}{l}\text { Level of occupational } \\
\text { activities }\end{array}$ & 3.00 & 2 & 95 & 0.57 \\
\begin{tabular}{l} 
Level of leisure activities \\
\hline
\end{tabular} & 0.25 & 1 & 96 & 0.62 \\
\hline
\end{tabular}

\section{Multiple Regression Analysis}

The second question examined the relationship between the Habitual Physical Activity Index and the Exercise Self-Efficacy index in relation to various demographic dimensions, including age, gender, martial, education and income in older adults.

The Habitual Physical Activity Index is divided into three sub-scales, household and family care, occupational, and leisure activity. Each sub-scale data was analyzed on various dimensions of demographic information and their relationship with Self-Efficacy using multiple regressions.

Multiple regressions are more powerful than correlation coefficients because they investigate casual relationships in which multiple independent variables are thought to affect a single dependent variable.

First, multiple regressions determined the relationships among household and family care activity, leisure activity, demographic variables and exercise Self-Efficacy. Results are based on 98 out of 124 participants. Occupational leisure activities were excluded because the majority of the participants are retired.

Before analyzing the relationship among Household and family care activity, demographic variables and exercise Self-Efficacy, in order to insure that the factor 
structure of the latent variables has closely related study factors, a measure model was used.

Pearson's correlation was used to determine collinearity among study variables in the sample as a whole. It measured the strength and direction of the connection between two internal-level variables. The total number of participants for the first test was 98 and accounted for $79 \%$ of the total number of participants. Table 5 indicates the correlation of each variable with each of the other variables in relation to the participants.

First, the variable of income was positively related with Education $(r=.67)$,

Marital status $(r=.67)$ and Self-Efficacy $(r=.48)$.

Table 5

Correlations of Study Variables in Entire Sample $(N=98)$

\begin{tabular}{|c|c|c|c|c|c|c|c|c|}
\hline Variable & $\begin{array}{l}\text { 1.Self- } \\
\text { Efficacy }\end{array}$ & 2.Age & 3.Gender & 4.Marital & 1 5.Education & 6.Income & $\begin{array}{c}\text { 7. Household } \\
\text { PA }\end{array}$ & $\begin{array}{c}\text { 8.Leisure } \\
\text { PA }\end{array}$ \\
\hline \multicolumn{9}{|l|}{ 1. Self-Efficacy } \\
\hline 2.Age & -0.36 & & & & & & & \\
\hline 3.Gender & -0.01 & 0.04 & & & & & & \\
\hline 4.Martial & $0.32 * *$ & -0.38 & -0.03 & & & & & \\
\hline 5.Education & $0.42 * *$ & -0.33 & 0.05 & $0.37 * *$ & & & & \\
\hline 6.Income & $0.48 * *$ & -0.37 & -0.08 & $0.67 * *$ & $0.67 * *$ & & & \\
\hline 7.Household PA & $0.27^{*}$ & -0.31 & -0.12 & 0.08 & $0.30 * *$ & $0.21^{*}$ & & \\
\hline 8. Leisure PA & $0.51^{* *}$ & -0.16 & 0.02 & $0.24 * *$ & $0.37 * *$ & $0.46 * *$ & $0.41 * *$ & \\
\hline
\end{tabular}

Note. ${ }^{*} p<.05 .{ }^{* *} p<.01$

The variable of leisure activity was positively related to Self-Efficacy $(r=.51)$,

Income $(r=.46)$, and Household and family care activity $(r=.41)$. The variable of Self-

Efficacy was positively related to Education $(r=.42)$ and Marital status $(r=.32)$.

However, Self-Efficacy was negatively related to Age $(r=-.36)$. 
The variable of household and family care activity was positively related to Education $(r=.30)$, Self-Efficacy $(r=.27)$ and Income $(r=.21)$. However, the variable of Self-Efficacy was negatively related to Age $(r=-.31)$.

The variable of income was positively related to Education $(r=.67)$, Marital Status $(r=.67)$ and Self-Efficacy $(r=.48)$ and Leisure activity $(r=.46)$. However, the variable of income was weakly related to Household and family care activity $(r=.21)$.

Last, the baseline of education was positively related with Self-Efficacy $(r=.42)$ and Martial $(r=.37)$. However, the correlation between Marital status and Age was negatively associated, with a Pearson's coefficient of -.38.

A normal probability plot (The P-P plot) of residuals determined if the data was approximately normally distributed. SPSS draws a 45 degree line and that represents the ideal normal distribution with means and standard-deviation of the sample. It was determined that the data was approximately normally distributed. As you can see, the points follow the line (see Figure 4). 


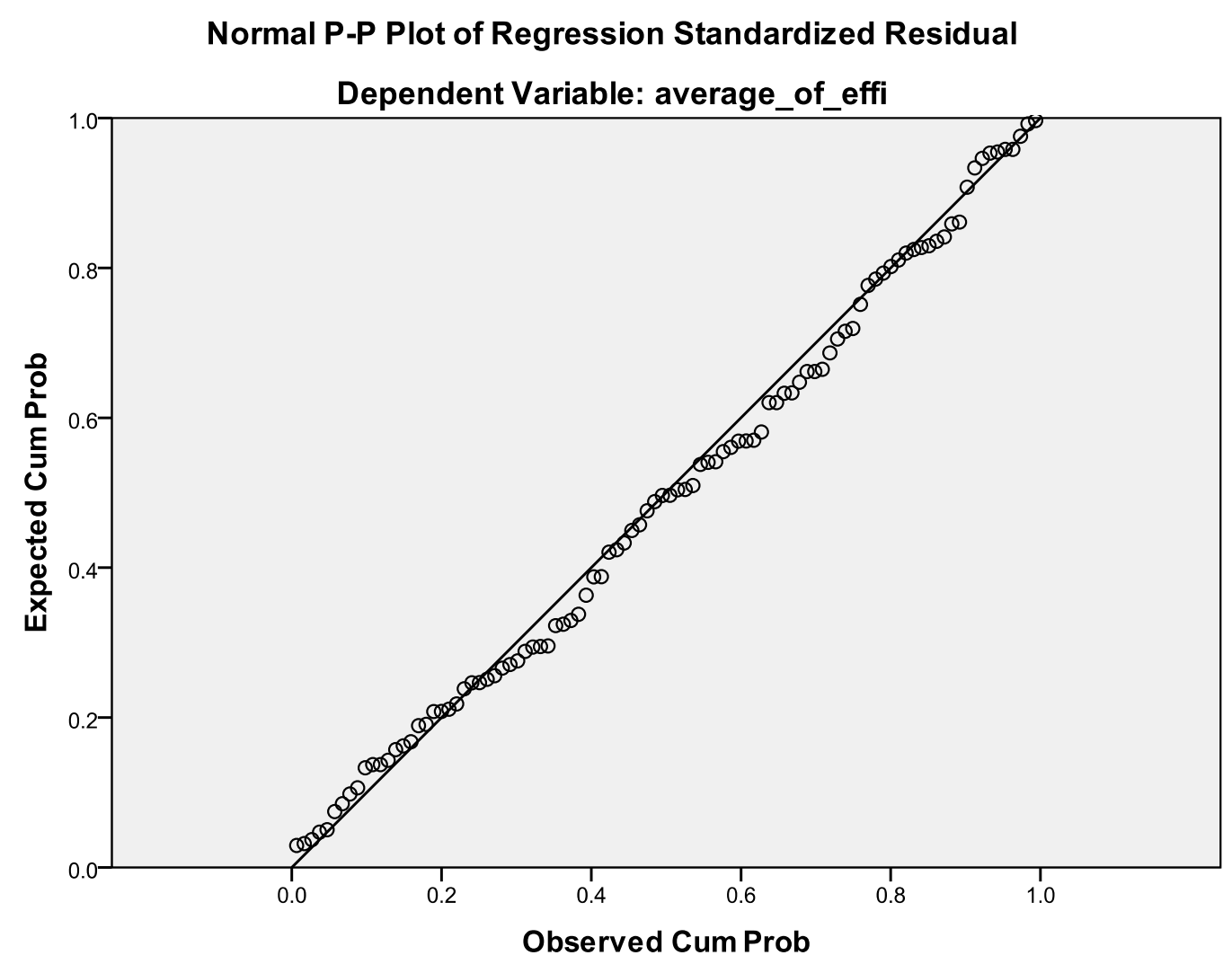

Figure 4. The Normal P-P Plot of Regression Standardized Residual Dependent Variable: Average of Self-Efficacy

Multiple regression analysis was conducted using the household and family care activity, leisure activity, age, gender, marital status, education and income levels as combined predictor variables and the Exercise Self-Efficacy Scale (ESES) as the dependent variable. The results show that exercise leisure activity is the primary effect on exercise Self-Efficacy.

This analysis identified leisure activity $(\beta=.37)$ as a positively significant predictor of exercise Self-Efficacy, accounting for $62 \%$ of the variance in the ESES $\operatorname{scores}\left(R^{2}=.38, p<.01\right)$. 
This analysis also identified age as a negatively significant predictor of exercise Self-Efficacy $(\beta=-.21)$, accounting for $62 \%$ of the variance in the ESES scores $\left(R^{2}=.38\right.$, $p<.001$ ). Table 6 provides a summary of multiple regression for predicting exercise SelfEfficacy scale.

Table 6

Summary of Multiple Regression for Predicting Exercise Self-Efficacy Scale

\begin{tabular}{ccccc}
\hline Variable & $\mathrm{B}$ & $\mathrm{SE}$ & $\beta$ & $\mathrm{t}$ \\
\hline Constant & 38.87 & 29.73 & & 1.31 \\
Age & -0.65 & 0.30 & $-0.21^{*}$ & -2.22 \\
Gender & 0.22 & 5.19 & 0.00 & 0.04 \\
Martial & 0.01 & 6.28 & 0.00 & 0.00 \\
Education & 2.56 & 3.02 & 0.10 & 0.85 \\
Income & 3.13 & 2.72 & 0.17 & 1.15 \\
Household PA & -0.78 & 4.96 & -0.02 & -0.16 \\
Leisure PA & 12.20 & 3.35 & $0.37^{* *}$ & 3.65 \\
\hline
\end{tabular}

Note. ${ }^{*} p<.05 .{ }^{* *} p<.01$

The relationship among Occupational Activity, demographic variables and exercise SelfEfficacy

Pearson's coefficienct was tested to determine the collinearity among study variables in the sample as a whole. The total sample numbers of participants for the first test were 29 of 124 . It accounted for $23 \%$ of total participants. The fact that 95 of participants were retired accounts for this. Therefore, the SPSS recognized the total number as 29 .

Table 7 indicates the correlation of each variable with each of the other variables in the samples of participants. The variable of income was highly related with Martial status $(r=.78)$, Education $(r=.66)$ and Self-Efficacy $(r=.40)$. This relationship had a positively strong association. 
Table 7

Correlations of Study Variables in Entire Sample $(N=29)$

\begin{tabular}{|c|c|c|c|c|c|c|c|}
\hline Variable & $\begin{array}{l}\text { 1. Self- } \\
\text { Efficacy }\end{array}$ & 2.Age & 3.Gender & 4.Martial & 5.Education & 6.Income & 7.Occupation \\
\hline \multicolumn{8}{|c|}{ 1. Self-efficacy } \\
\hline 2.Age & -0.30 & & & & & & \\
\hline 3.Gender & 0.08 & 0.10 & & & & & \\
\hline 4.Martial & $0.37^{*}$ & -0.14 & -0.02 & & & & \\
\hline 5.Education & $0.31^{*}$ & -0.20 & 0.05 & $0.32 *$ & & & \\
\hline 6.Income & $0.40^{*}$ & -0.17 & -0.08 & $0.78^{* *}$ & $0.66 * *$ & & \\
\hline 7.Occupation & 0.19 & -0.27 & -0.22 & 0.15 & -0.40 & -0.20 & \\
\hline
\end{tabular}

Note. $* p<.05 . * * p<.01$

The variable of education was negatively related to Occupational physical activity $(r=-.40)$ indicating that increasing values of education were associated with decreasing values of occupational physical activity. The variable of education was positively related to Martial Status $(r=.32)$ and Self-Efficacy $(r=.31)$.

Last, the baseline of education was positively related with Self-Efficacy $(r=.42)$ and Martial Status $(r=.37)$. However, the correlation between Marital status and Age was negatively associated, with a Pearson's coefficient of -.38.

The normal probability plot (The P-P plot) of residuals determined if the data was approximately normally distributed. As noted above, the small circle points follow along the diagonal line to determine whether the data was approximately normally distributed or not. The points close to a diagonal line and the residuals appear to be approximately normally distributed. Thus, the assumptions for regression analysis appear to be met (see Figure 5) 


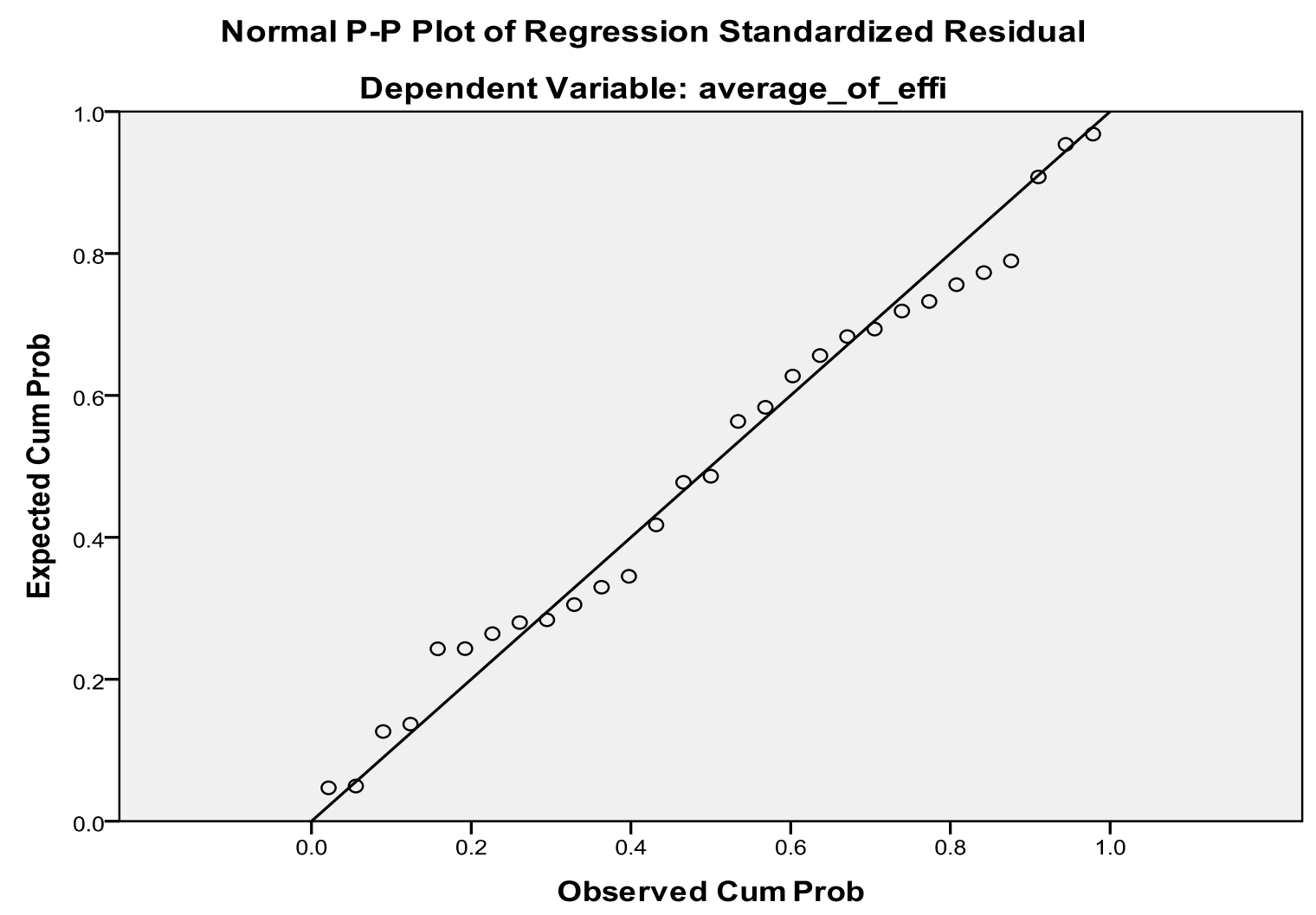

Figure 5. The Normal P-P Plot of Regression Standardized Residual Dependent Variable: Average of Self-Efficacy

Multiple regression analysis was conducted using occupational activity, age, gender, marital status, education and income as a combined predictor variable and Exercise Self-Efficacy Scale (ESES) as the dependent variable. This analysis indicates no significant predictor of exercise Self-Efficacy exists, accounting for $31 \%$ of the variance in the ESES scores $\left(R^{2}=.32, p<.05\right)$. 


\section{CHAPTER V \\ DISCUSSION}

\section{Introduction}

This study asks two research questions. First, what is the relationship between exercise self-efficacy and level of physical activity among older adults? And if such a relationship exists, is it measurable? In this study, "exercise" refered to consistent exercise and/or activities associated with movements of the body, and is central to the meaning of physical self-efficacy. Second, what relationship exist in exercise selfefficacy and physical activity level by age, gender, marital status, level of education, and level of income among older adults?

The study is based on data collected from 124 adults recruited from two community senior centers and one volunteer program in Muncie Indiana. Most of the participants were older adults and more likely to regularly attend community programs than the overall population of the region. This study could apply only to the middle-class, that is, to highly educated women and men over the age of 50 who live in a middle town area.

This chapter discusses the implications of the study as well as the limitations of the study. The people involved in the study, many already retired, regularly participated in a variety of community activities and in a variety of communities. They were actively involved in some form of regular physical activity suggesting that this group may well be healthier and more focused on remaining healthy than older people not involved in such activities. 


\section{Age and Gender}

The mean age of the participants was 69.3 years of age, 50 years representing the youngest and 90 the oldest. The majority of the participants ranged in age from 60 years to 69 years $(\mathrm{N}=46,37.1 \%)$ and the second largest group ranged in age from 70 years to 79 years $(\mathrm{N}=41,33.1 \%)$. Their retirement may play a significant factor in the amount of time and energy they are able to devote to such involvement.

People who participated in regular exercise groups such as chair exercise, yoga, tai -chi, line dancing and the walking club provided the data for the study. These physically active programs take place on a regular basis and the participants in the various programs attended regularly. For instance, the yoga class meets every Tuesday at 11:00 a.m. at CCVA. The walking club is offered every Tuesday and Thursday between 9:30 a.m. and 10:30 a.m. in the Basketball Arena Lounge at Ball State University. Regular participation in these programs requires a commitment of time, of energy and a desire, and willingness to engage consistently in physical activities.

More women $(\mathrm{N}=97,78.2 \%)$ participated in the study than did men $(\mathrm{N}=27$, $21.8 \%$ ). The female participants engaged in a wider range of senior programs offered by community organizations and they also maintained larger social networks than the male participants. Even after retirement, the social worlds and networks of many men remain primarily connected to their earlier professional work and career. They also see themselves and are seen by others more in terms of their children than in terms of individual persons. Older men tend to remain in touch with friends and neighbors they have known over several years rather than create new friendships in the context of community organizations (Edward, Thompson Jr., Patrick \& Whearty, 2004). 
Burda, Vaux and Schill (1984) argue that older men's relational networks are important for maintaining their identity, even when the networks are smaller and less clustered than women's. This remains true even if and when the social connections yield less emotional support. This may reflect the idea that men not only have fewer emotional relationships, but that such relationships are of less importance to men than to women.

Whereas Caucasians accounted for $85 \%$ of the total number of participants, African Americans accounted for 15 percent of the total, the latter's presence limited to participation in the Snap-2-It program. According to the U.S. Census Bureau, in 2005 Caucasians accounted for 79.6 percent of residents 55 years of age and older whereas 9.1 percent of the population consisted of African Americans. The number of caucasians and the number of African Americans did not represent the make-up of the U.S. population as of 2005. One limitation of the study is that no Hispanics participated because no Hispanic people were involved in the three programs used for the study.

\section{Marital Status}

In 2005 in the U.S., the proportion of men 55 years of age and older who were married and living with their spouse (74\%) was more than women in the same age group (51\%). Of the participants in this study, the number of people who were married and living with his or her spouse was $50 \%$, the percentage being equal for both men and women. The marital status of the participants in the study and reports from U.S. Census Bureau (2005) reflect no significant differences in the marriage category. 


\section{Education}

Ninety-three percent of the participants in this study were high school graduates. According to the 2005 Annual Social and Economic Supplement (U.S. Census Bureau, 2005), $82 \%$ of people in the U.S. who were 55 years of age and older were high school graduates. As people became older, graduation rates went down. Only $86 \%$ of the population between the ages of 55 years and 65 years were high school graduates. The percentage of high school graduates dropped to $70 \%$ when the population was 75 years of age and older.

The following numbers indicate the various levels of education completed by the participants (these numbers reflect the highest level of education obtained). Nine of the 124 participants completed either elementary or middle school, a graduation rate of $7.2 \%$. Fifty-five of the 124 people completed high school, a graduation rate of $44.4 \%$. Twentyfour of the 124 participants completed college, a graduation rate of $19.4 \%$. Thirty-six people completed a graduate program (Masters or Doctoral degrees), for a graduation rate of $29 \%$. From the shape of the frequency distribution, the highest point of education was the completed high school graduation.

Furthermore, high school graduation rates differences between 2005 U.S. Census Bureau and the study results were small. Nearly $50 \%$ of the participants had at least a bachelor's degree or higher. This was a high percentage compared to the 2005 U.S Census Bureau reports. According to the Annual Social and Economic Supplement (U.S. Census Bureau, 2005), 22.6\% of adults 55 years of age and over had a bachelor's or higher degree. 
Education is an important element throughout a person's life because of the many benefits it brings to the degree holder. Education not only provides a person with basic skills and resources, but also fosters the development of talents, skills and abilities and provides a better opportunity for a person's success.

Krause (2007) indicates that older adults with higher levels of education demonstrated and used their talents and abilities more effectively. In addition, Krause indicates that older adults with higher levels of education hold to and believe in a greater sense of the meaning of life than do those with lower levels of education. Finally, older adults who hold to a strong sense of the meaning of life are also better able to express a feeling of being grateful.

Income

In 2005, the poverty rate for people 65 years of age and older was 10 percent (U.S Census Bureau, 2005). The present study found similar results. Thirteen percent of the participants $(n=16)$ reported a household income of less than $\$ 10.000$ annually. Further, $43 \%$ of the participants earned over $\$ 35.000$ a year.

\section{Interpretation of Findings}

The current study examined two research questions to address the merit of these hypotheses:

(1) What is the relationship between exercise self-efficacy and level of physical activity among older adults? 
(2) What relationship exist in exercise self-efficacy and physical activity level by age, gender, marital status, level of education, and level of income among older adults?

First research question: What is the relationship between exercise self-efficacy and level of physical activity among older adults?

A one-way ANOVA was used to address the first research question regarding the relationship between the Habitual Physical Activity Index (HPAI) and the Exercise SelfEfficacy Scale (ESES). The Habitual Physical Activity index has three sub-groups scales: (1) household and family care, (2) occupational and (3) leisure activity. Only the participants in the moderate or regular leisure activity group showed significant exercise self-efficacy scores.

Previous studies indicate that older adults who engage in regular physical activity improve not only their physical well-being but also their psychological well being, especially in terms of self-efficacy. First of all, the positive effects of regular exercise on the physical health of older adults are well documented. One important benefit is a reduced risk for developing chronic diseases, the maintenance of a healthy weight and lowering the risk of premature death (Goodpaster, Costill, Trappe, \& Hughes, 1996, Wang, Ramey, Schettler, Hubert, \& Fries, 2002, Wojtek et al., 2009).

Williams (1998) states that runners over age 60 who run longer distances display significantly higher levels of plasma high-density lipoprotein cholesterol (HDL; the "good" cholesterol) along with lower adiposity, blood pressure and triglycerides.

Recent studies demonstrate that the effects of regular exercise on the psychological well-being of older adults is positive and significantly helpful in matters 
relating to self-efficacy. Albert Bandura's $(1977,1997)$ social cognitive theory of selfefficacy is particularly useful in explaining the positive effects of consistent physical activity among older adults in the United States. Self-efficacy is significantly correlated with one's physical condition and the maintenance of a healthy body.

A strong correlation is also operative at the sub domain-level of efficacy variables such as physical self-worth and an overall sense of self-efficacy, both in a six month period and a one year period (McAuley et al, 2005, McAuley, Mihalko, \& Baneet, 1997).

Perkins, Multhaup, Perkins, and Barton (2008) argue that self-efficacy in both physical and social activities increases participation in physical activities for older adults in both Spain and the United States. Other studies indicate that self-efficacy contributes both to weight loss and weight control (Glynn and Ruderman, 1986, Kaphingst, et al 2007, Sallit, Ciccazzo, and Dixon, 2009,), as well as the overall quality of life and satisfaction with one's life in older adults (Pang, Eng and Miller, 2007). These studies demonstrate that physical activity increases a sense of self-efficacy and satisfaction with the quality of life. Thus, participants who regularly engage in physical activities, have higher levels of self-efficacy.

This study found no significant differences between household and family care activity scales in exercise self-efficacy scores. However, the study has raised interesting topics regarding household and family care activity. This study found that a small number of people were acting as caregivers either for a child or elderly person. Three participants ( $2 \%)$ out of the 124 participants cared for a child or children who were two years of age or younger. Five participants (4\%) cared for a child or children between 2 and 5 years of 
age. Ten participants $(8 \%)$ cared for a child with a disability or an elderly person with special needs. Very few participants acted as caregivers.

Problems included the age of the participants, their own physical health, and a failure to earn enough money to provide the level of care they wanted to provide. Thus, "caregiving" might well be an interesting topic for future study because caregiving is one of the most significant concerns in public health at the national level. National Alliance for Caregiving reported in 2004 that 44.4 million Americans were at that time caregivers. This means that more than 21 percent of the adult population (people 18 years of age and older) were primary caregivers, and many of them provided unpaid care for a family member, friend or neighbor. Such caregivers were present in an estimated 22.9 million households (National Alliance for Caregiving \& AARP, 2004)

The study found no significant differences between occupational activity variables on exercise self-efficacy scores. One-way ANOVA statistics recognized 29 participants as the total number of people because 95 participants $(77 \%)$ were retired from their work. Therefore, most of the results showed that there were no significant differences. In terms of occupation, 8 out of 29 participants were either a schoolteacher or advisor. Participants worked at a variety of jobs including factory worker, site manager, computer program coordinator, nursing assistant, certified pharmacist, clericalbookkeeper and secretary.

Second research question: What relationship exists in exercise self-efficacy and physical activity level by age, gender, marital status, level of education, and level of income among older adults? 
Multiple regression analysis were used to measure the relationship of the independent variables including, household and family care activity, leisure activity, age, gender, marital status, level of education, and income level with the dependent variable scores from the Exercise Self-Efficacy Scale (ESES).

Multiple regressions used between a dependent variable (self-efficacy) and two or more independent variables (physical activity and demographic information) to predict outcomes.

There were only two dependent variables significantly related with exercise selfefficacy. First, age was negatively related to exercise self-efficacy, which meant that as people got older, their level of exercise self-efficacy decreased. The study result showed that age was a negatively significant predictor of exercise self-efficacy, accounting for $62 \%$ of the variance in the exercise self-efficacy scores. Second, leisure activity was positively correlated with exercise self-efficacy, which meant that when people did more leisure activity, their level of exercise self-efficacy increased.

Gaithersburg (1999) and Davis-Berman (1989) mentioned that older adults may have lower self-efficacy than young people. Self-efficacy expectations and level of selfefficacy become simply lower in older adults with their approach to general and day-today living situations. This explanation concluded that lower self-efficacy expectations are part of the aging process for older adults.

Daniel (1996) stated that aged experience correlated more negatively with exercise self-efficacy expectations and provided several reasons that would involve more barriers for the older adults than younger adults. 
In older adults, it was likely that health status or disabilities were main obstacles to improving their health. Their movement became more painful when they were old, because they had difficulty with balance and had a fear of falling. Therefore, it caused to reduce exercise self-efficacy expectation such as such as strength, magnitude, and generality (Daniel, 1996 \& Lee, Arthur, and Avis, 2007).

Outcome expectations are also likely to be lower in older adults during exercise. There was very little research done on exercise and outcome expectations, but Marcus, Rakowski and Rossi (1992) studied to find out the relationship between exercise efficacy and outcome expectation of older adults using 10 participants from a local senior citizen's center. The most common negative outcome reported was that exercise provided discomfort for them, including pain, shortness of breath, and stiffness, both during and after an exercise session. One participant had issued a statement that outcome expectations were low among older adults, simply because they were old, and the entire study group agreed with that. Furthermore, a couple of participants reported that a doctor had told them to avoid exercise because of heart or lung problems. However, this data provided only a few insights.

Older adults had less exercise experience compared to young adults, even though health behavior, including exercise, produced their health and wellness. Healthy People 2010 reported that only $31 \%$ of the population between the ages of 65 years and 74 years were performing the recommended amounts of physical activity: 20 minutes of moderate physical activity 3 or more days per week. However, only $13 \%$ of them were performing vigorous physical activity for 5 or more days per week 30 minutes of moderate activity per day. Moreover, $77 \%$ of the population over the ages of 75 was not engaging in 
moderate physical activity, and $94 \%$ of them did not engage in vigorous physical activity in 1997. The majority of young adults are more physically active than older adults, according to Health People 2010. $36 \%$ of the population between ages of 18 to 24 years was performing moderate physical activity and $32 \%$ of them were performing vigorous physical activity (Public Health Service, 2000).

Clark (1995) also mentioned that more than $75 \%$ of the older population did not engage any types of regular exercise through the full year, and few older adults have participated in community based physical activity.

This study assumed (A) that physical abilities would decrease as people became older and, in conjunction with that assumption, (B) that as physical abilities decreased, so would exercise self-efficacy. In this study, though leisure activity significantly predicts exercise self-efficacy, household and family care, occupational activity did not predict exercise self-efficacy.

\section{Limitations of the Study}

First, the results of this study are not representative of the overall population. Most of the participants were Caucasian, middle-class, highly educated people over the age of 55 who live in a middle town area. The data and conclusions of this study do not reflect the ethnic diversity, for example, Asian, Hispanics, and African American, of the United States.

Second, the results of this study cannot be applied to the larger population of the United States because participation was limited to an older age group. The participants regularly attended community programs at a higher rate than the general population of the region. The participants regularly joined in exercise groups such as yoga, tai-chi, line 
dance, and chair exercise. In general, the level of physical activity for older people is extremely low. The participants of this study, however, engaged in a higher level of physical activity and obtained higher scores on the exercise self-efficacy scores than did the general population of people in these age groups.

Third, those people who agreed to fill out the questionnaires and participate in the study may be more interested in physical activity and its effect on their exercise selfefficacy level than the overall population. This may reflect that the participants are parts of groups that support and share their activity and the opportunity for easier access to exercise facilities.

Many factors play a role in the level of self-efficacy of older adults. Self-efficacy is a person's belief in his or her ability to succeed in a particular situation. These beliefs consist of a person's feelings, thoughts, motivations and conduct. A strong sense of physical efficacy reinforces a person's sense of personal attainment and a sense of a person's overall wellbeing, and does this in a variety of ways. People with selfconfidence are able to manage exceptionally difficult tasks and are, therefore, less likely to give up their efforts to accomplish tasks.

Glanz, Rimer, and Lewis (2002) determined that environmental factors might affect a person's self-efficacy. Behavior is not, of course, generated in full by environmental factors and cannot be measured only on the basis of the environment. Neither can the environmental factors be measured solely by personal behaviors. According to Bandura (1999), behavior reflects a dynamic interaction of personal determinants, already existing behaviors and environmental factors. Triadic causation, however, provides no singular and strait lines to account for reciprocal interaction. Each 
factor affects the level of activities, situational circumstances, socio-structural constraints and opportunities. But, at the same time, the categories affect the factors.

Survey questionnaires inquiring about physical activity are more socially acceptable for gaining information but such questionnaires are not able to obtain an objective measure of physical activity. Therefore, the relationship between physical activity levels and self-efficacy may not be answered as accurately as it would be with objective measuring of physical activity. This study cannot determine conclusively if behavior changes were real in terms of an objective means of measurement.

\section{Suggestions for the Future Research}

1. This study should be replicated with a larger sample size. The questionnaire was provided to participants who joined the CCVA (Community Center for Vital Aging) and FPSC (Forest Park Senior Center) programs in the spring and summer semester of 2010. Thus, participants who are not currently enrolled in the programs could not be sampled.

The participants answered several important elements, such as age, gender, educational background, physical activity and exercise self-efficacy that contributed to their answers. Nevertheless, it might be expected that a larger number of participants would strengthen the statistical numbers.

2. The study should be replicated using a longer time period to gain accurate information about the self-efficacy scales of both physical activity and demographic information. In addition, the study focused on information gained from self-reporting of the main variables. This study tried to factor in this limitation by using previously validated paper-and-pencil instruments. In the future, study must include data based on 
direct observation. For instance, physical activity can be somewhat determined by pedometers, interviews, direct observation, motion sensors, and logs (Langan and Marrotta, 2000).

3. The study focused on relationships that exist between Habitual Physical Activity and Exercise Self efficacy. But, it did not focus on detailed questions from the questionnaires. For instance, what's the relationship between levels of income and amount of time given to grocery shopping? One would expect such a study to show that people who have higher levels of income go grocery shopping more often than people with lower levels of income. The question concerning the kinds of physical activity done and the relationship of that activity to leisure time was not asked.

4. The questionnaires must be changed in any future study of older adults. For instance, an occupation questionnaire may not be needed in that the majority of older adults are retired. In addition, question number 27 asked the primary sport they had played during the past month. The questionnaires provided a list of the activities. Most participants responded that they walked or gardened, both requiring low levels of physical activity. But, the list they were given was limited to high levels of physical activity, such as boxing, badminton, basketball, football, judo, soccer, and volleyball. These are not the kinds of activity older adults normally participate in. Future studies will need a more realistic list of sports played by older adults.

\section{Conclusion}

The relationships between the Habitual Physical Activity Index (HPAI) and the Exercise Self-Efficacy Scale (ESES) that generate specific demographic information are complex for older adults. But, several conclusions can be drawn. 
The primary purpose of this study was to identify the dimensions relating to older adults based on the exercise self-efficacy scale in Midwest, Indiana. Different levels of leisure activity were similar based on the scores of their exercise self-efficacy responses. However, no differences were observed for the exercise self-efficacy scale by habitual and occupation physical activity. The conclusion indicated that some differences were observed between level of physical activity and exercise self-efficacy.

The secondary purpose was to do multiple comparisons of demographic information. The results indicate that significant differences are found between age and exercise self-efficacy. Younger adults indicated that moderate and regular physical activity positively affected their exercise self-efficacy. 


\section{REFERENCES}

Atchley, R. C. (2000). Social forces and aging. ( $9^{\text {th }}$ ed.). Belmont, CA: Wadsworth Thomson Learning.

Bandura, A. (1977). Self-Efficacy: Toward a Unifying Theory of Behavioral Change. Psychology Review 84, 191-215.

Bandura, A. (1986). Social foundations of thought and action: A social cognitive theory, Englewood Cliffs, New Jersey: Prentice-Hall.

Bandura, A. (1992). Self-Efficacy Mechanisms in Physiological Activation and Health Promoting Behavior. In Adaption, Learning, and Affect. New York: Raven Press.

Bandura, A. (1994). Self-efficacy. In V. S. Ramachaudran (Ed.), Encyclopedia of human Behavior, 4, 71-81. New York: Academic Press.

Bandura, A. (1997). Self-efficacy. Harvard Mental Health Letter, 13(9), 4.

Bandura, A. (1997). Self-efficacy: The exercise of control. New York: W.H. Freeman and Company.

Bandura, A. (1999). A social cognitive theory of personality. Handbook of personality (2nd ed.) New York: Guilford Publications.

Bandura, A. (2001). Social cognitive theory: An Agentic approach. Annual Review of Psychology, 52, 1-26.

Bandura, A. (2006). Guide for constructing self-efficacy scales. Self-efficacy beliefs of adolescents, 5, 307-337. Greenwich, CT: Information Age Publishing. 
Baecke, J. A. H., Burema, J., \& Frijiters, J. E. (1982). A short questionnaire for the measurement of habitual physical activity in epidemiological studies. The American Journal of Clinical Nutrition, 36, 936-942.

Bess, H. M., \& LeighAnn, H. F. (2003) Motivating people to be physically active. Champaign, IL: Human Kinetics.

Brawley, L. R., \& Rogers, W. M. (1993). Social psychological aspects of fitness promotion. In P. Seraganian (Ed.), Exercise psychology: The influence of physical exercise on psychological processes, 254-298. New York, NY: Wiley.

Bromberger, J. T., \& Costello, E. J. (1992). Epidemiology of depression for clinicians. Social Work, 37, 120-125.

Burda, P. C., Vaux, A., \& Schill, T. (1984). Social support resources: Variation across sex and sex role. Personality and Social Psychology Bulletin, 10, 119-126.

Burns, K. J., \& Froman, R. D. (1997). Refinement of the Habitual Physical Activity Index for use with American adults. Journal of Nursing Measurement, 5(1), 17 32.

Center for Disease Control and Prevention. (1996). Physical Activity and Health Energize Your Life. Retrieved October 24, 2008, from http://www.cdc.gov/nccdphp/dnpa/physical/terms

Center for Disease Control (1999). Chapter 2: Historical Background and Evolution of Physical Activity Recommendations. Historical Document: November 17, 1999. Retrieved October 2, 2008, from http://www.cdc.gov/nccdphp/sgr/chapcon.htm 
Center for Disease Control and Prevention. (n.d.). A Report of the Surgeon General Physical Activity and Health. At a glance 1996. Retrieved September 5, 2008, from http://www.cdc.gov/nccdphp/sgr/pdf/sgraag.pdf.

Center for Disease Control and Prevention. (2000). A report of the surgeon general patterns and trends in physical activity. Retrieved February 24, 2009, from http://www.cdc.gov/nccdphp/sgr/pdf/sgrfull.pdf.

Center for Disease Control (2006). State Data Highlights. Document Abstract. Retrieved October 2, 2008, from http://www.cdc.gov/tobacco/data_statistics/ state_data/data_highlights/2006/index.htm.

Center for Disease Control and Prevention. (2008). Physical Activity and Health the Benefits of Physical Activity. Retrieved October 11, 2008, from http://www.cdc.gov/physicalactivity/everyone/health/index.html.

Center for Disease Control and Prevention. (2008). What person age 50 and older can do Retrieved November 22, 2008 from http://www.cdc.gov/hiv/topics/over50/protection.htm

Center for Disease Control and Prevention. (2008). Healthy aging for older adults. Retrieved November 30, 2008 from http://www.cdc.gov/aging/.

Cervone, D., \& Pervin, L. A. (2008). Personality Theory and research. (10 ${ }^{\text {th }}$ ed.). Hoboken, New Jersey: John Wiley \& Sons, INC.

Chambliss, C. A., \& Murray, E. J. (1979). Efficacy attribution, locus of control of weight loss. Cognitive Therapy and Research, 3, 349-353. 
Cheung, S. K., \& Sun, S. Y. K., (2000). Effects of self-efficacy and social support on the mental health conditions of mutual-aid organization members. Social Behavior and Personality, 28, 413-422. Retrieved October 2, 2008, from http://findarticles.com/p/articles/mi qa3852/is 200001/ai n8899528.

Clark, D. O. (1995). Racial and educational differences in physical activity among older adults. The gerontologist, 35, 472-480.

Comings, J., Parrella, A., \& Soricone, L. (2000). Helping adults persist: four supports. National Center for the Study of Adult Learning and Literacy. Retrieved October 2, 2008, from http://www.ncsall.net/.

Corbin, C. B. (2008). Physical activity for everyone: What every educator should know about promoting lifelong physical activity. Journal of Teaching in Physical Education, 21, 128-135.

Daniel, O. C. (1996). Age, Socioeconomic Status, and Exercise Self-Efficacy. The Gerontologist, 36(2), 157-164.

Davis-Berman, J. (1989). Physical Self-Efficacy, Perceived Physical Status, and Depressive Symptomatology in Older Adults. The Journal of Psychology, 124(2).

Dino, G., Kamal, K., Horn, K., Kalsekar, I., \& Fernandes, A. (2004). Stage of change and smoking cessation outcomes among adolescents. Addictive Behaviors, 29(5). 395-940.

Doherty, T. J. (2003). Ageing and sarcopenia. Journal of Applied Physiology, 95(4), 1717 $-1727$. 
Edward, H., Thompson Jr., Patrick, M., \& Whearty. (2004). Older Men’s Social Participation: The Importance of Masculinity Ideology. The Journal of Men's Studies, 13(1), 5-24.

Frontera, W. R., Hughes, V. A., Fielding, R. A., Fiatarone, M. A., Evans, W. J., \& Roubenoff, R. (2000). Aging of skeletal muscle: a 12-year longitudinal study, Journal of Physiology, 88, 1321 - 1326.

Gaithersburg, K. D. (1999). Healthy Aging: Challenges and Solutions, Gaithersburg, MD. Aspen Publishers, Inc., 36.

Gecas, V. (1989). The social psychology of self-efficacy. Annual review of sociology, 15, 291-316.

Gilinsky, N. J. (2010). Physical Activity and Self-regulatory Capabilities: Examining relationships with academic self-efficacy and academic outcomes. Doctoral dissertation, Texas Tech University.

Glanz, K., Rimer, B.K., \& Lewis, F.M. (2002). Health Behavior and Health Education. Theory, Research and Practice. San Fransisco: Wiley \& Sons.

Gleeson-Krieg, J. (2004) Daily Activity: effects on physical activity self-efficacy and behavior in people with type 2 diabetes. Doctoral dissertation, University of Connecticut.

Goodpaster, B. H., Costill, D. L., Trappe, S.W., \& Hughes, G. M. (1996). The relationship of sustained exercise training and bone mineral density in aging male runners. Scandinavian journal of medicine \& science in sports. 6(4), 216-221.

Glynn, S. M., \& Ruderman, A. J. (1986). The development and validation of an eating self-efficacy scale. Cognitive Therapy and Research, 10(4), 403-420. 
Grembowski, D., Patrick, D., Diehr, P., Durham, M., Beresford, S., Kay, E \& Hecht, J. (1993). Self-efficacy and health behavior among older adults. Journal of Helath and Social Behavior, 34, 89-104.

Hagberg J. M., Allen, W. K., Seals, D. R., Hurley, B. F., Ehsani, A. A., \& Holloszy, J. O. (1985) A hemodynamic comparison of young and older endurance athletes during exercise. Journal of Applied Physiology. 58, 2041-2046.

Harridge, S., Magnusson, G., \& Saltin, B. (1997). Life-long endurance-trained elderly men have high aerobic power, but have similar muscle strength to nonactive elderly men. Aging Clinical and Experimental Research, 9, 80 - 87.

Indiana State Department of Health. (1994). Indiana health behavior risk factors: 1994. Indianapolis, IN: Epidemiology Resource Center.

Indiana State Department of Health. (2000). Indiana health behavior risk factors: 2000. Indianapolis, IN: Epidemiology Resource Center.

Kaphingst, K. A., Bennett, G. G., Sorensen, G., Kaphingst, K.M., O’Neil, A. E.,\& McInnis, K. (2007). Body mass index, physical activity, and dietary behaviors amongmemebrs of an urban community fitness center: a questinonnaire survey. BMC Public Heatlh. 7, 181-189. doi: 10.1186/1471-2458-7-181

Kowalski, S. D. (1997). Self-efficacy and self-efficacy as predictors of success in smoking cessation. Jorunal of Holistic Nursing, 15, 128-142.

Krause, N. (2007) Self-Expression and Depressive Symptoms in Late Life. Research on Aging 29(3). 187-206. 
Langan, M. E., \& Marotta, S. A. (2000). Physical Activity and Perceived Self-Efficacy in Older Adults. Adultspan Journal, Retrieved October 3, 2010, from http://www.accessmylibrary.com/article-1G1-79030130/physical-activity-andperceived.html

Lee, L. L., Arthur, A., \& Avis, M. (2007). The role of self-efficacy in older people's decisions to initiate and maintain regular walking as exercise-Finding from a qualitative study. Preventive Medicine, 45, 62-65.

Lent, R.W., Brown, S. D., \& Larkin, K. C. (1987). Comparison of three theoretically derived variables in Predicting career and academic behavior: Self-efficacy, interest congruence, and consequence thinking. Journal of Counseling Psychology, 34, 293-298.

Maciejewski, P. K., Prigerson, H. G., \& Mazure, C. M. (2000). Self-efficacy as a mediator between stressful life events and depressive symptoms: Differences based on history of prior depression. The British Journal of Psychiatry, 176, 373 $-378$.

Magaletta, P. R., \& Oliver, J. M. (1999). The hope construct, will, and ways: Their relations with self-efficacy, optimism, and general well-being. Journal of Clinical Psychology. 55 (5). 539-551.

Marcus, B. H., Selby, V. C., Niaura, R. S., \& Rossi, J. S. (1992). Self-efficacy and the stage of exercise behavior change. Research Quarterly for Exercise and Sport, 63, 60-66. 
McAuley, E., Mihalko. S. M., \& Bane, S.M. (1997). Exercise and Self-Efficacy in Middle-Aged Adults: Multidimensional Relationships and Physical Fitness and Self-Efficacy Influences. Journal of Behavioral Medicine, 20(1), 67-83.

McAuley, E., Elavsky. S., Molt, R.W., Konopack, J. F., Hu, L., \& Marquez, D.X. (2005). Physical Activity, Self-Efficacy, and Self-Esteem: Longitudinal Relationships in older adults. Journal of Gerontology: Psychological sciences, 60, 268-275.

Morris, K. S., McAuley, E., \& Motl, R, W. (2008). Neighborhood satisfacation, functional limitation, and self=efficacy influences on physical activity in older women. The International Journal of Behavioral Nutrition and Physical Activity, 5(13). doi: 10.1186/1479-5868-5-13.

National Alliance for Caregiving and AARP. (2004). Caregiving in the U.S MetLife Foundation Retrieved September 3, 2010, from http://www.caregiving.org/data/04finalreport.pdf

Pajares, F., Hartley, J., \& Valiante, G. (2001). Response format in writing self-efficacy assessment. Greater discrimination increases prediction. Measurement and Evaluation in Counseling and Development, 33, 214-221.

Pang, M. YC., Eng, J. J., \& Miller, W. C. (2007). Determinants of satisfaction with community reintegration in older adults with chronic stroke: role of balance selfefficacy. Physical Therapy, 87(3), 282-291. doi: 10.2522/ptj.20060142.

Perkins, J. M., Multhaup, K. S., Perkins, H.W., \& Barton, C. (2008) Self-Efficacy and Participation in Physical and Social Activity among Older Adults in Spain and the Unived States. The Gerontologist, 48(1), 51-58. 
Public Health Service. (1996). Physical Activity and Health: A Report of the Surgeon General. Washington, D C: U.S. Government Printing Office.

Public Health Service. (2000). Healthy People 2010; Physical activity and fitness U.S Department of Health and Human Services. Washington D.C: U.S. Government Printing Office.

Queensland University of Technology (2008, May 2). Weight Loss Possible When Selfbelief High. ScienceDaily. Retrieved October 2, 2008, from http://www.sciencedaily.com/releases/2008/05/080502082735.htm.

Resnick, B., \& Jenkins, L. (2000). Testing the Reliability and Validity of the SelfEfficacy for Exercise Scale. Nursing Research, 49, 154-159.

Resnick, B., Luisi, D., Vogel, A., \& Junaleepa, P. (2004). Reliability and Validity of the Self-Efficacy for Exercise and Outcome Expectations for Exercise Scales with Minority Older Adults. Journal of Nursing Measurement, 12(3), 235-248.

Sallit, J., Ciccazzo, M., \& Dixon, Z. (2009). A Cognitive-Behavioral Weight Control Program Improves Eating and Smoking Behaviors in Weight-Concerned Female Smokers. Journal of the American Dietetic Association, 109(8), 1398-1405.

Semmar, Y. (2006). Adult learners and academic achievement: The roles of self-efficacy, self-regulation, and motivation, Education Resources Information Center. ED 491441 Retrieved October 2, 2008, from http://www.eric.ed.gov/.

Shephard, R. J. (1997). Aging, Physical Activity, and Health. Champaign (IL): Human Kinetics; 1997. 66.

Shobha, S., Liam R. O., \& Allen. D. (2003) Creating health communities, healthy homes, healthy people: Initiating a research agenda on the built environment and public health. American Journal of Public Health, 93, 1446. 
Strecher, V. J., DeVellis, B. M., Becker, M.H., \& Rosenstock, I.M. (1986). The Role of Self-Efficacy in Achieving Health Behavior Change. Health Education \& Behavior, 13, 73-92.

Turnquist, S. P. (2009). Aging and Endurance athletes. Outsourced Administrative \& Secretarial Services. Retrieved September 26, 2009, from http://www.susansplace.org/blog/aging-and-the-endurance-athlete/.

U.S. Census Bureau (2005). Older Adults in 2005. Retrieved September 2, 2010, from http://www.census.gov/population/www/pop-profile/files/dynamic/OLDER.pdf.

U.S. Department of Health and Human Services. (2009, January). Physical Activity Guideline for Americans. Rockville, MD: Retrieved September 25, 2009, from http://www.hhs.gov/.

Wang, B.W., Ramey, D.R., Schettler, J. D., Hubert, H.B., \& Fries, J. F. (2002). Postponed development of disability in elderly runners: a 13-year longitudinal study. Archives of Internnal Medicine, 162, 2285-2294.

Weber, B., Robert, B., Resnick, M., Deimling, G., Zauszniewski, J., Musil, C., \& Yarandi, H. N. (2003). The effect of dyadic intervention on self-efficacy, social support, and depression for men with prostate cancer. Physcho-Oncology, 13(1), 47-60.

West, R. L., Welch, D. C., \& Thorn, R.M. (2001). Effects of goal setting and feedback on memory performance and beliefs among older and younger adults. Psychology and Aging, 16, 240-250.

William, A. S. (2006). Epidemiology of Aging: An Ecological Approach. Sudbury, Massachusetts: Jones and Bartlett Publishers. 
Williams, P. T. (1998). Coronary heart disease risk factors of vigorously active sexagenarians and septuagenarians. Journal of the American Geriatrics Society, 46(2), 134-142.

White, S. M., Wojcicki, T. R., \& McAuley, E. (2009). Physical activity and quality of life in community dwelling older adults. Health and Quality of Lift Outcomes, 7(10).

Wojtek, J. C., David, N. P., Maria, A. F., Christopher. T. M., Claudio, R. N., George, J. S., \& James S. S., (2009). Exercise and physical activity for older adults. Medicine \& Science in Sports \& Exercise, 41 (7), 1510-1530 Special Communications: Position Stand.

Zeldin, A. L., \& Pajares, F. (2000). Against the odds: self-efficacy beliefs of women in mathematical, scientific, and technological careers. American Educational Research Journal, 31 (1), 215-246. doi: 10.3102/00028312037001215. 
APPENDIX A

PROTECTING HUMAN SUBJECT RESEARCH PARTICIPANTS

HUMAN SUBJECT APPROVAL LETTER 
Protecting Human Subject Research Participants

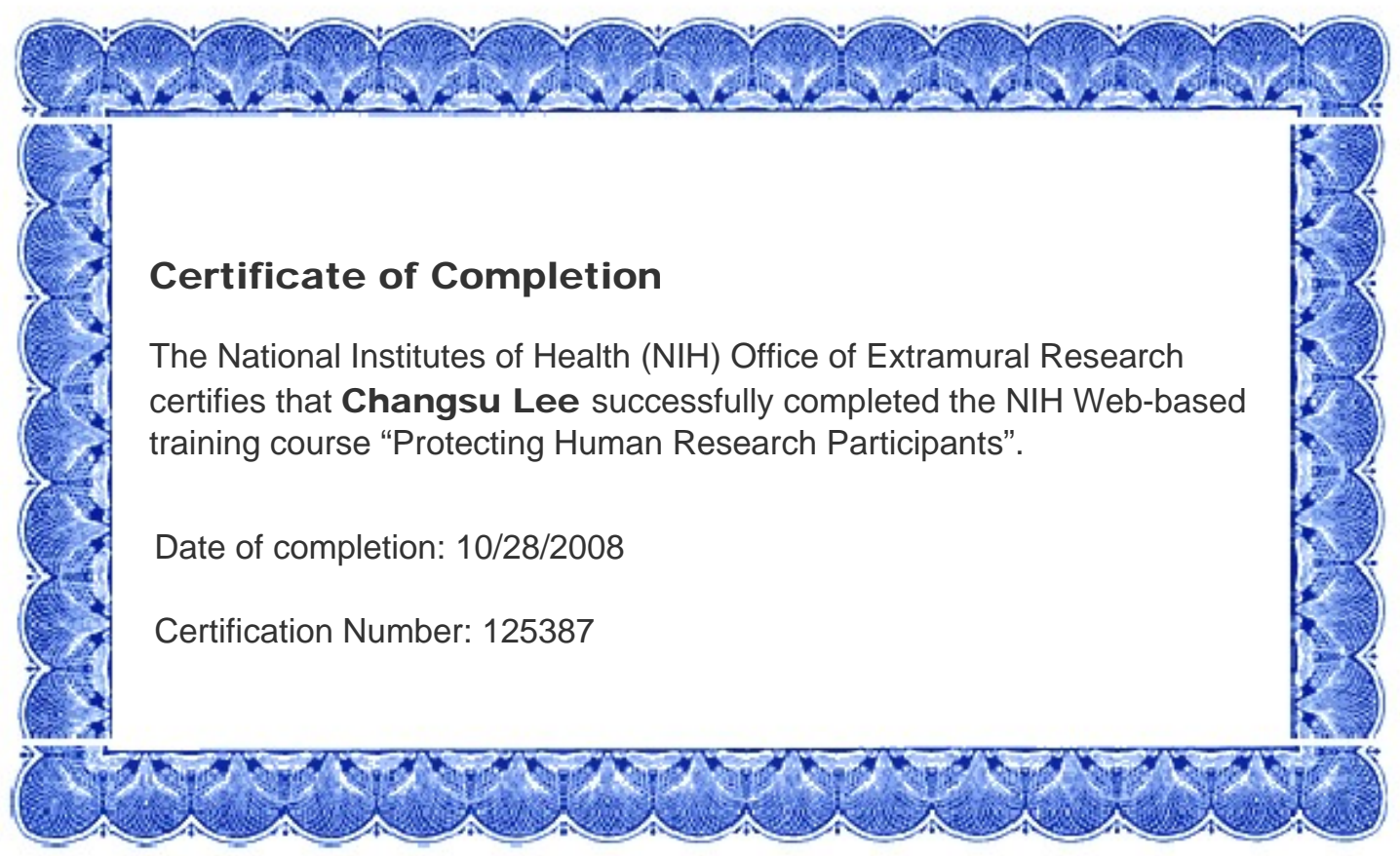




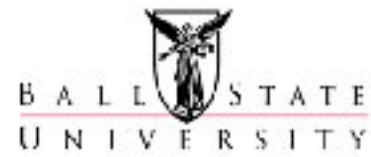

\title{
Institutional Review Board
}

\author{
DATE: January 13, 2010 \\ TO: $\quad$ changsu lee \\ FROM: $\quad$ Ball State University IRB \\ RE: $\quad$ IRB protocol \# 148281-1 \\ TITLE: $\quad$ Self-Efficacy and physical activity in older Adults \\ SUBMISSION TYPE: New Project \\ ACIION: $\quad$ DETERMINATION OF EXEMPT STATUS \\ DECISION DATE: January 13,2010
}

The Institutional Review Baard reviewed your protocol on January 13, 2010 and has determined the procedures you have proposed are approp riate for exemption under the federal regulations. As such, there will be no further review of your protocol, and you are cleared to proceed with the procedures outlined in your protocol. As an exempt study, there is no requirement for continu ing review. Your protocol will remain on file with the IRB as a matter of record.

While your project does not require continuing review, it is the responsibility of the P.I. (and, if applicable, faculty supervisor) to inform the IRB if the procedures presented in this protocol are to be modified or if problems related to human research participants arise in connection with this project. Any procedural modifications must be evaluated by the IRB before being implemented, as some modifications may change the review status of this project. Please contact Amy Boos at (765) 285-5034 or akboos@bsu.edu if you are unsure whether your proposed modification requires review or have any questions. Proposed modifications should be addressed in writing and submitted electronically to the IRB (http://www.bsu.edu/irb) for review. Please reference the above IRB protocol number in any communication to the IRB regarding this project.

Reminder: Even though your study is exempt from the relevant federal regulations of the Common Rule (45 CFR 46, subpart A), you and your research team are not exempt from ethical research practices and should therefore employ all protections for your participants and their data which are appropriate to your project. 
APPENDIX B

COVER LETTER 


\section{Cover Letter}

Dear Residents,

My name is Changsu Lee. I am a graduate student working toward a Doctoral Degree in Adult, Higher and Community education at Ball State University in Muncie Indiana. I need of participants for my study. I am an international student and interested in study about self-efficacy and physical activity in older adults.

The purpose of this research project entitled "Self-Efficacy and physical activity in older Adults" is to examine the relationship between self-efficacy for physical activity and the level of physical activity for older adults who live in Delaware County, Indiana. This study will also examine the relationship between self-efficacy and the level of physical activity through various demographic dimensions.

For this project, you will be asked to complete the three main questionnaires. These will measure demographic data sheet, physical activity and physical activity selfefficacy. The demographic data sheet will record information about age, gender, Marital Status, educational level, and income level. 30 item questionnaires for your physical activity patterns in and around the house during the past month. You will be also asked to complete aself-administered18-tiem questionnaires to measure your self-efficacy beliefs in exercise.

Participation in this research is voluntary. Do not write your name or any type of identification on the questionnaire. No individual resident's results will be reported for any reason. Participants can quit at any time and choose not to answer any questions that you wish. All of data will be anonymous. The information gathered will be handled in a confidential manner and you will not be identified in data analysis or later reports.

If you have any questions regarding your rights as a human research participant, you may contact the Coordinator of Research Compliance, Ball State University, Muncie IN 47306, (765) 285-5070 or irb@bsu.edu.

Completion of the questionnaire should not take more than 20 minutes. Please complete the questionnaire and return it to me as soon as possible. For your convenience, I have enclosed a prepaid box to mail the questionnaires back with my mailing address.

Yours truly,

Investigator

Changsu Lee

2000 N. Oakwood Ave. Apt 202

Muncie In 47304

(765)730-1775

E-mail: cslee@bsu.edu
Advisor

Joseph Armstrong, Ph.D

Adult, Higher and Community Education

Ball State University

Muncie, IN 47306

(765)285-5475

E-mail: jarmstrong@bsu.edu 
APPENDIX C

THE LETTER OF AGREEMENT

(THE COMMUNITY CENTER FOR VITAL AGING) 
March 20, 2010

The Fisher Institute for Wellness and Gerontology

PL 225

Ball State University

Muncie, IN 47306

Dear Judy Elton

My name is Changsu Lee. I am a graduate student working toward a Doctoral Degree in Adult, Higher and Community education at Ball State University in Muncie Indiana. I need of participants for my study. I am an international student and interested in study about self-efficacy and physical activity in older adults.

The purpose of this research project entitled "Self-efficacy and physical activity in older Adults" is to examine the relationship between self-efficacy for physical activity and the level of physical activity for older adults who live in Delaware County, Indiana. This study will also examine the relationship between self-efficacy and the level of physical activity through various demographic dimensions.

Please indicate your approval of this permission by signing the letter where indicated below and returning to me as soon as possible. With your permission, I can survey for this study. Your assistance is greatly appreciated. If you have any question or concerns, please contact me.

Sincerely,

Changsu Lee (Investigator)

(765)730-1775

E-mail: cslee@bsu.edu

Permission granted:

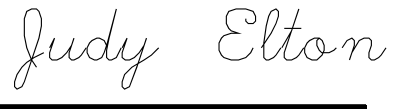

Signiture

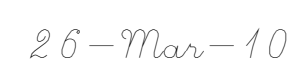

Date 
APPENDIX D

THE LETTER OF AGREEMENT (THE FOREST PARK SENIOR CENTER) 
April 20, 2010

2517 West $8^{\text {th }}$ Street

Muncie, IN 47306

765-289-0844

Dear Bruce Reynolds

My name is Changsu Lee. I am a graduate student working toward a Doctoral Degree in Adult, Higher and Community education at Ball State University in Muncie Indiana. I need of participants for my study. I am an international student and interested in study about self-efficacy and physical activity in older adults.

The purpose of this research project entitled "Self-efficacy and physical activity in older Adults" is to examine the relationship between self-efficacy for physical activity and the level of physical activity for older adults who live in Delaware County, Indiana. This study will also examine the relationship between self-efficacy and the level of physical activity through various demographic dimensions.

Please indicate your approval of this permission by signing the letter where indicated below and returning to me as soon as possible. With your permission, I can survey for this study. Your assistance is greatly appreciated. If you have any question or concerns, please contact me.

\section{Sincerely,}

Changsu Lee (Investigator)

(765)730-1775

E-mail: cslee@bsu.edu

Permission granted:

\section{Bruce Reynolds}

Signiture

$\frac{20-A p r-10}{\text { Date }}$

Date 
APPENDIX E

THE LETTER OF AGREEMENT

(THE RETIRED SENIOR VOLUNTEER PROGRAM) 
June 5, 2010

520 E. Main Street

Muncie, IN 47305

765-289-4541

Dear Neal Miller

My name is Changsu Lee. I am a graduate student working toward a Doctoral Degree in Adult, Higher and Community education at Ball State University in Muncie Indiana. I need of participants for my study. I am an international student and interested in study about self-efficacy and physical activity in older adults.

The purpose of this research project entitled "Self-efficacy and physical activity in older Adults" is to examine the relationship between self-efficacy for physical activity and the level of physical activity for older adults who live in Delaware County, Indiana. This study will also examine the relationship between self-efficacy and the level of physical activity through various demographic dimensions.

Please indicate your approval of this permission by signing the letter where indicated below and returning to me as soon as possible. With your permission, I can survey for this study. Your assistance is greatly appreciated. If you have any question or concerns, please contact me.

Sincerely,

Changsu Lee (Investigator)

(765)730-1775

E-mail: cslee@bsu.edu

Permission granted:

Seal Mriller.

Signiture
5-Jun-10

Date 
APPENDIX F

DEMOGRAPHIC DATA SHEET 
1. Age $(\quad)$

2. Gender: Male $(\quad)$, Female $(\quad)$

3. Marital Status

Single (never married, divorced, separated or widowed)

Married

4. Years of completed education

Elementary

Middle School

High School

College

University (including Master and Doctoral degree)

5. Household income level: Please check one (Single House Income. Do not include other income sources) $<\$ 10.000$

$\$ 10.000-\$ 19.999$ $\$ 20.000-\$ 34.999$

$\$ 35.000-\$ 49.999$

$\$ 50.000+$ 
APPENDIX G

HABITUAL PHYSICAL ACTIVITY INDEX 
Habitual Physical Activity Index

\section{Household and Family Care Activities}

Please describe your activities at home, not including activities you may do at your home or other people's homes for pay. If you did not do that activity, mark "none".

During the past month, how much time did you spend...

1. Caring for a child or children under 2 years of age? None or $<1$ hour a week $\geq 1$ but $<20$ hours a week $\geq 20$ hours a week

2. Caring for a child or children between 2 and 5 years of age?

None or $<1$ hour a week $\geq 1$ but $<20$ hours a week $\geq 20$ hours a week

3. Caring for a disabled child or elderly person (only count time actually spent in feeding, dressing, moving, etc.)

4. Preparing meals or cleaning up from meals on weekdays?

None or $<1$ hour a week $\geq 1$ but $<20$ hours a week $\geq 20$ hours a week

None or $</ 1 \frac{1}{2}$ hour a week $\geq 1 / 2$ hour but $<1$ hours a day $\geq 1$ hour but $<1 \frac{1}{2}$ a day $\geq 1 / 2$ hours but $<2$ hours a day $\geq 2$ hours a day

5. Preparing meals or cleaning up from meals on weekends?

None or $</ 1 \frac{1}{2}$ hour a week $\geq 1 / 2$ hour but $<1$ hours a day $\geq 1$ hour but $<1 \frac{1}{2}$ a day $\geq 1 / 2$ hours but $<2$ hours a day $\geq 2$ hours a day

6. Doing major cleaning, such as shampooing carpets, waxing floors, or washing walls or windows?

None or $<$ once a month Once a month 2-3 times a month

Once a week More than once a week 
7. Doing routine cleaning such as dusting, laundry, vacuuming, or changing linens?

8. Going grocery shopping and pushing a shopping cart?

9. Doing gardening or yard work, such as moving lawn or ranking leaves?

10. Doing heavy outdoor work, such as chopping wood, tilling soil, shoveling snow, or baling hay?

11. Doing major home decoration or repair, such as plumbing, tiling, painting or building?
None or $<$ once a month

Once a month

2-3 times a month

Once a week

More than once a week

None or $<$ once a month

Once a month

2-3 times a month

Once a week

More than once a week

None or $<$ once a month

Once a month

2-3 times a month

Once a week

More than once a week

None or $<$ once a month

Once a month

2-3 times a month

Once a week

More than once a week

None or $<$ once a month

Once a month

2-3 times a month

Once a week

More than once a week 
2. Occupational Activities

Please describe activities you did as part of your employment in the past month

12. What is your occupation?

What is your primary specific activity (For example, selling cars, keeping account books, etc.)

How many hours a week do you work?

13. At work I sit

Never Seldom Sometimes $\quad$ Often Always

14. At work I stand

Never Seldom Sometimes $\quad$ Often Always

15. At work I walk

Never Seldom Sometimes $\quad$ Often Always

16. At work I lift heavy loads

Never Seldom Sometimes $\quad$ Often Always

17. After working I am tired due to physical activity

Never Seldom Sometimes $\quad$ Often Always

18. At work I walk I sweat due to physical activity
Never
Seldom
Sometimes
Often
Always

19. In comparison with others of my own age I think my work is physically
Much heavier
Heavier
As heavy
Lighter Much lighter 


\section{Leisure Activities}

This section asks about your physical activity during your leisure time in the past Month

20. In comparison with others of my own age I think my physical activity during leisure time is
Much more
More The Same
Less
Much less

21. During leisure time, I sweat due to physical activity

Never Seldom Sometimes Often Very often

22. During leisure time, I play sport

Never Seldom Sometimes Often Very often

23. During leisure time, I sit or recline

Never Seldom Sometimes Often Very often

24. During leisure time, I walk

Never Seldom Sometimes Often Very often

25. During leisure time, I exercise at a class or club

Never Seldom Sometimes Often Very often

26. During leisure time, I exercise at home

Never Seldom Sometimes Often Always

Look at the sports listed below. If you participate in any of these or similar activities, continue with question 27 . If you do not play sports, you are finished with the questionnaire.

$\begin{array}{lll}\text { Archery } & \text { Cross country } & \text { Rowing } \\ \text { Athletics(track and field) } & \text { Running } & \text { Sailing } \\ \text { Badminton } & \text { Cycling } & \text { Soccer } \\ \text { Basketball } & \text { Fishing } & \text { Skiing } \\ \text { Billiards } & \text { Football } & \text { Swimming } \\ \text { Bowling } & \text { Gardening } & \text { Squash rackets } \\ \text { Boxing } & \text { Golf } & \text { Tennis } \\ \text { Canoeing } & \text { Horse riding } & \text { Volleyball } \\ \text { Cricket } & \text { Judo } & \end{array}$


27. Which sport did you play most often in the past month?

(fill in the blank)

28. How many hours a week?

Less than one hour

1 hours but less than 2

2 hours but less than 3

3 hours but less than 4

4 or more hours

29. If you play a second sport, which sport was it?

(fill in the blank)

30. How many hours a week?

Less than one hour

1 hours but less than 2

2 hours but les

s than 3

3 hours but less than 4

4 or more hours 
APPENDIX H

EXERCISE SELF-EFFICACY SCALE 


\section{Exercise Self-Efficacy Scale}

DIRECTIONS: A number of situations are described below that can make it hard to stick to exercise regularly ( 3 or more times a week). On the items below, please rate your confidence that you can perform exercise on a regular basis. Please rate your degree of confidence by recording in each of the blank spaces a number from 0 to 100 using the scale below.

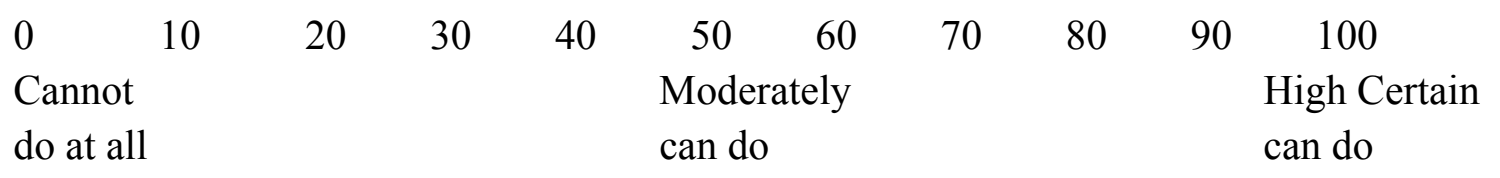

1. When I am feeling tired.

2. When I am feeling under pressure from work.

3. During bad weather.

4. After recovering from an injury that caused me to stop exercising.

5. During or after experiencing personal problems.

6. When I am feeling depressed.

7. When I feeling anxious.

8. After recovering from an illness that caused me to stop exercising.

9. When I feel physical discomfort when I exercise.

10. After a vacation.

11. When I have too much work to do at home.

12. When visitors are present.

13. When there are other interesting things to do.

14. If I don't reach my exercise goals.

15. Without support from my family or friends.

16. During a vacation.

17. When I have other time commitments.

18. After experiencing family problems. 